\title{
Arrival angle anomalies of Rayleigh waves observed at a broadband array: a systematic study based on earthquake data, full waveform simulations and noise correlations
}

\author{
H.A. Pedersen, ${ }^{1,2}$ P. Boué, ${ }^{1,3}$ P. Poli ${ }^{1,4}$ and A. Colombi ${ }^{5}$ \\ ${ }^{1}$ University of Grenoble Alpes, ISTerre, F-38041 Grenoble, France. E-mail: Helle.Pedersen@ujf-grenoble.fr \\ ${ }^{2}$ CNRS, ISTerre, F-38041 Grenoble, France \\ ${ }^{3}$ Department of Geophysics, Stanford University, Stanford, CA 94305, USA \\ ${ }^{4}$ Department of Earth, Atmospheric and Planetary Sciences, Massachusetts Institute of Technology, Cambridge, MA, USA \\ ${ }^{5}$ Department of Mathematics, Imperial College London, South Kensington Campus, London
}

Accepted 2015 September 9. Received 2015 September 2; in original form 2015 June 16

\begin{abstract}
SUMMAR Y
Deviation of seismic surface waves from the great-circle between source and receiver is illustrated by the anomalies in the arrival angle, that is the difference between the observed backazimuth of the incident waves and the great-circle. Such arrival angle anomalies have been known for decades, but observations remain scattered. We present a systematic study of arrival angle anomalies of fundamental mode Rayleigh waves (20-100 s period interval) from 289 earthquakes and recorded by a broadband network LAPNET, located in northern Finland. These observations are compared with those of full waveform synthetic seismograms for the same events, calculated in a 3-D Earth and also compared with those of seismograms obtained by ambient noise correlation. The arrival angle anomalies for individual events are complex, and have significant variations with period. On average, the mean absolute deviation decreases from $\sim 9^{\circ}$ at $20 \mathrm{~s}$ period to $\sim 3^{\circ}$ at $100 \mathrm{~s}$ period. The synthetic seismograms show the same evolution, albeit with somewhat smaller deviations. While the arrival angle anomalies are fairly well simulated at long periods, the deviations at short periods are very poorly modelled, demonstrating the importance of the continuous improvement of global crustal models. At 20-30 s period, both event data and numerical simulations have strong multipathing, and relative amplitude changes between different waves will induced differences in deviations between very closely located events. The source mechanism has only limited influence on the deviations, demonstrating that they are directly linked to propagation effects, including near-field effects in the source area. This observation is confirmed by the comparison with seismic noise correlation records, that is where the surface waves correspond to those emitted by a point source at the surface, as the two types of observations are remarkably similar in the cases where earthquakes are located close to seismic stations. This agreement additionally confirms that the noise correlations capture the complex surface wave propagation.
\end{abstract}

Key words: Interferometry; Surface waves and free oscillations; Seismic tomography; Wave scattering and diffraction; Wave propagation.

\section{INTRODUCTION}

Surface waves used for imaging the lithosphere and asthenosphere typically have wavelengths between some tens to $1000 \mathrm{~km}$. Considering the length scales and amplitude of the lateral heterogeneities, the hypothesis underlying most surface wave tomography methods are not respected (e.g. perturbation theory, ray theory) but these methods have still been remarkably successful in providing robust earth models. Complex propagation effects may be at least partly corrected for when the source and receivers are located within the study area (e.g. Snieder 1986; Friederich 2003; Chen et al. 2007; Fichtner et al. 2013) or when the local structure is imaged below a large array (e.g. Friederich \& Wielandt 1995; Bruneton et al. 2002; Chevrot \& Zhao 2007; Lin \& Ritzwoller 2011; Salaün et al. 2012).

The assumption that the surface waves propagate along or close to the great-circle on which source and receiver are located remains of practical importance for many teleseismic surface wave tomographies, such as methods based on two-station phase velocities and methods that take into account finite frequency effects calculated around the great-circle path. In practice, the commonly observed 
arrival angle anomaly, that is the difference between the theoretical great-circle arrival angle (backazimuth) and the observed one, illustrates that this great-circle assumption is generally not met. Even though the local arrival angle anomaly may be the result of complex propagation effects, it is often interpreted as the result of the seismic ray deviating from the great-circle. Therefore the term great-circle deviation is often used both to designate the local deviation and the difference between the great-circle and actual source-receiver path in a ray-geometrical framework.

The scope of this work is to provide systematic and quantified observations of arrival angle anomalies with the aim of giving input to the methods that are fully or partly dependent on the assumption of great-circle propagation. We focus on fundamental mode Rayleigh waves, which still dominate surface wave studies. In contrast to Love waves and higher mode Rayleigh waves, they are mainly forwards scattered (Snieder 1986) which may at least partly explain why Rayleigh wave tomography yield robust results even though the underlying hypothesis are not valid.

Techniques to observe arrival angle anomalies at seismic stations can be separated into polarization analysis and array processing. The former (e.g. Vidale 1986; Lerner-Lam \& Park 1989; Laske 1995; Laske \& Masters 1996; Yoshizawa et al. 1999; Larson \& Ekström 2002; Zhang et al. 2003; Ferreira \& Woodhouse 2007) gained interest because they could be used to identify station misalignment (e.g. Laske 1995; Laske \& Masters 1996; Ekström \& Busby 2008) and used as additional input to ray-based inversions (e.g. Laske 1995; Laske \& Masters 1996; Laske \& Masters 1998; Yoshizawa et al. 1999). The polarization measurements are however particularly challenging: as the great-circle deviation (and therefore the arrival angle anomaly), is frequency dependent, the polarization and instantaneous frequency must be estimated simultaneously. Local noise, higher modes, or other interfering waves created by scattering and/or diffraction will consequently perturb the analysis. The latter problem is particularly true below $50 \mathrm{~s}$ period (e.g. Paulssen et al. 1990).

Early array studies demonstrated effects of surface wave propagation anomalies (Bungum \& Capon 1974), but array techniques aimed at observing arrival angle anomalies have mainly gained momentum over the last decade due to the increase of seismic broadband coverage (e.g. Cotte et al. 2000; Baumont et al. 2002, 2004; Tanimoto \& Prindle 2002; Maupin 2011; Alvizuri \& Tanimoto 2011; Foster et al. 2014b). Such techniques are based on variants of time or frequency domain beamforming (for an overview see Rost \& Thomas 2002), a technique which is used for a large range of applications in seismology. Using a small array in the French Alps, Cotte et al. (2000) showed that stable measurements are possible down to $20 \mathrm{~s}$ period even when the local lithospheric structure beneath the array is complex. It is possible to correct two-station phase velocities using the effective arrival angle (backazimuth, angle measured clockwise from north) observed by beamforming rather than the great-circle assumption. This technique was successfully applied by Baumont et al. (2002), Bourova et al. (2005), Kaviani et al. (2007) and more recently by Foster et al. (2014a). Tanimoto \& Prindle (2007) used a similar approach, but used average corrections for any given azimuth. Beamforming has also been used in lithospheric imaging to obtain the average phase velocities beneath an array of many seismic stations. Such techniques were for example applied in the Baltic Shield by Bruneton et al. (2004), Maupin (2011) and Pedersen et al. (2013). In these studies, the estimated backazimuth is a side product, as the phase velocity and propagation direction are estimated simultaneously (e.g. Maupin 2011). Beamforming may help to constrain lateral heterogeneities, as demon- strated by the observation of deviations created by the contrast in lithospheric structure across the Tornquist-Teisseyre Zone (Alsina \& Snieder 1996).

A coherent picture of arrival angle anomalies is only slowly emerging through these diverse studies, a gap that the present study aims at diminishing. We tentatively summarize the result of some of these studies, acknowledging that scattered observations exist also beyond the references cited here. Cotte et al. (2000) estimate that the large anomalies (up to $30^{\circ}$ ) observed in the French Alps at 30 s period can be explained by a combination of large-scale ray deviations and local refraction due to local crustal thickening. This hypothesis explains at least partly why Alsina et al. (1993) observed relatively small arrival angle anomalies $\left(\sim 8^{\circ}\right)$, as their beamforming used an array covering all of Spain, far too large to capture effects induced by local heterogeneities in the receiver area. All observations at hand do however agree on an overall decrease of arrival angle anomalies with period (e.g. figure 10 of Zhang et al. 2003), but they may remain constantly high below $50 \mathrm{~s}$ period (e.g. Maupin 2011). Overall, the arrival angle anomalies (and their variations with period) are complex, and depend not only on backazimuth, but also on some finer degree of source location (Cotte et al. 2000; Zhang et al. 2003; Maupin 2011; Foster et al. 2014b). Using earthquakes recorded by the USArray Transportable Array, Foster et al. (2014b) demonstrated that it is possible to obtain lateral variations of great-circle deviations across all of the United States. They subsequently modelled these deviations using ray based approximations and full waveform modelling. Large wavelength features were well modelled, but the fit to the short wavelengths was poor, indicating more complex crust and upper mantle structure than was accounted for in the global models.

In this work, we carry out a systematic calculation of arrival angle anomalies as observed on data from the POLENET-LAPNET broad-band array, installed in northern Finland from 2007 to 2009 (Fig. 1). The crustal structure beneath the array is laterally fairly homogeneous, with a few kilometres variation in crustal thickness (e.g. Poli et al. 2013; Silvennoinen et al. 2014). The main change in crustal thickness takes place at the coastline, but the closest coastline is not a continent-ocean transition, as the crust is continental across the Barents Sea. Finally, using an array of several hundred kilometres aperture reduces the effect of local heterogeneities. Given the wavelength considered $(70-400 \mathrm{~km})$, we can to a first order expect that observed arrival angle anomalies are not created by local crustal heterogeneity or topography in the receiver area, but rather linked to large-scale propagation effects between source and the LAPNET array, possibly also influenced by heterogeneities locally on the source side. This study is therefore complementary to that of Foster et al. (2014b) who focus on variations in arrival-angle anomalies on the receiver side.

In this paper, we first present the data sets (earthquake data, numerical simulations and noise correlations) and the methods we used for arrival angle measurements. We then present results of deviations for the recorded earthquakes, first across all events and subsequently the spatial variations across the source areas for different periods. These results are compared to arrival angle anomalies observed on the synthetic seismograms computed for the same earthquakes. Finally, we compare the observations based on earthquake records with those obtained using surface waves extracted from ambient noise correlation between each station of the LAPNET array and seismic stations worldwide. Such data correspond to a particularly simple source, but ideally take into account propagation effects whether in the near-field or far-field. 

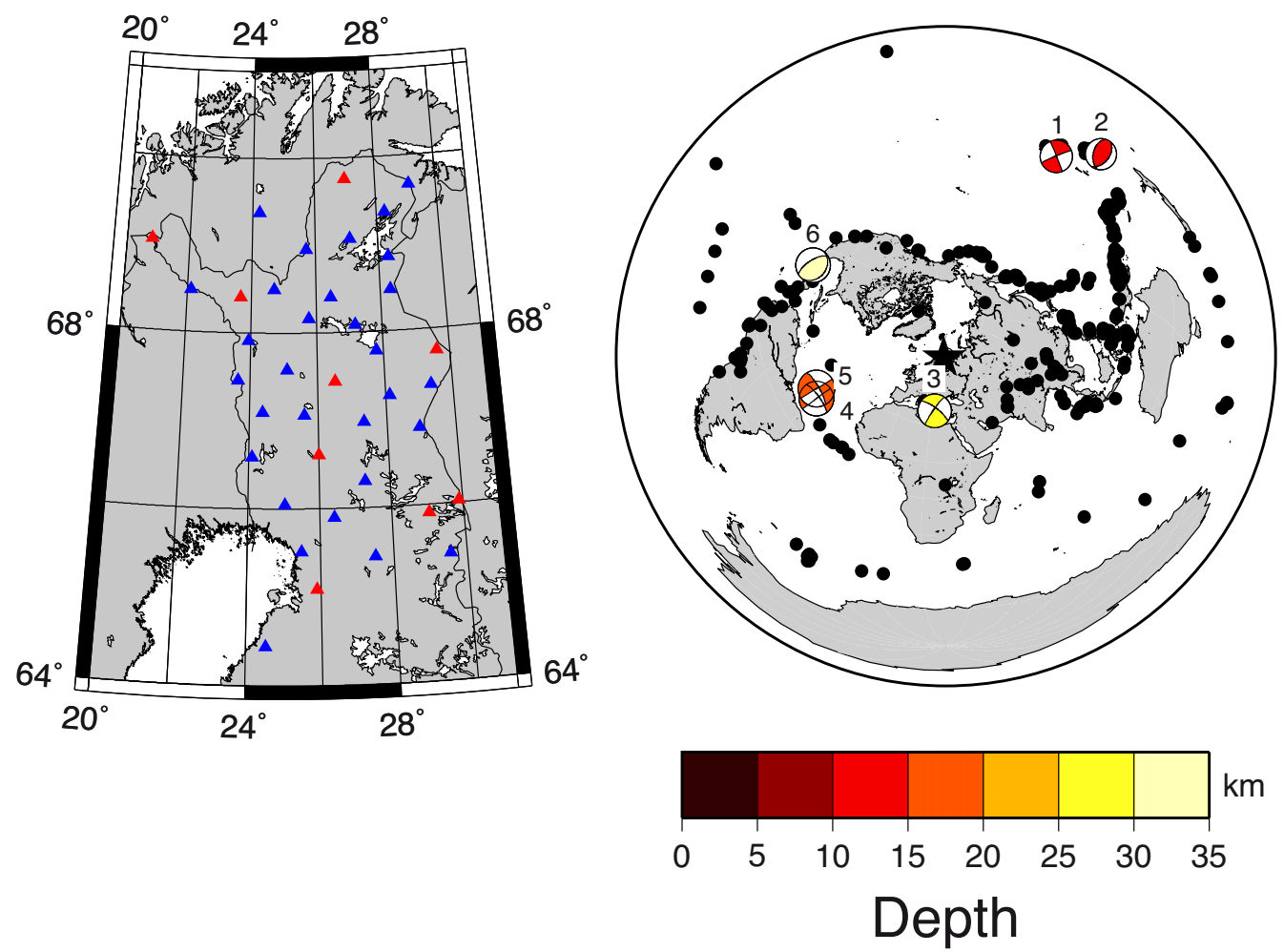

Figure 1. LAPNET/POLENET Array and events. Left-hand panel: seismic stations used in this study, shown by triangles for permanent (red) and temporary (blue) stations. Right-hand panel: events. Six illustrative events discussed in Section 3.1 are also shown. The colour scale shows the depth of the selected events. The black star is placed at the centre of the LAPNET/POLENET array. The project used (Azimuthal Equidistant projection) respects directions and relative distances to the centre of the projection (here, the centre of the array).

\section{DATA AND DATA ANALYSIS}

\subsection{Earthquake data}

The LAPNET/POLENET temporary seismic array $(\sim 275 \mathrm{~km} \times$ $\sim 460 \mathrm{~km}$ ) was installed for a period of two and a half years between 2007 and 2009, as part of the International Polar Year. It was composed of 39 broad-band stations and recorded 289 teleseismic events of magnitude $>6$ (see Fig. 1) which were extracted from the continuous data set using the earthquake catalogue distributed by the National Earthquake Information Center (http://earthquake.usgs.gov/earthquakes), updating event information once available via the Global Centroid-Moment-Tensor (CMT) Project (http://www.globalcmt.org/; Dziewonski et al. 1981; Ekström et al. 2012). We applied standard pre-processing, including decimation and correction for instrument response, on this data set. We then extracted the fundamental mode Rayleigh wave using frequency-time filtering (FTAN, Levshin et al. 1989). For each event, we used data from a high-quality permanent station (SGF) to define a reference frequency-time filter, with manual inspection at each step. We then applied the same filter to all other stations, adjusting for different epicentral distances. The flat part of the time window around the phase-collapsed signal was $200 \mathrm{~s}$, that is twice the maximum period. An example of pre-processed data can be found in Fig. S1. It should be noted that frequency-time filters applied on single-station data can suppress signals of the same frequency that arrive at different times while wave trains within the same time window can neither be identified nor separated with this type of filter. As seen in Section 3, multipathing remains present at short periods for many events.

\subsection{Synthetic seismograms}

To complement the analysis of the azimuthal deviations, real data observations from the POLENET/LAPNET array were paired with synthetic seismograms calculated with SPECFEM3D (Komatitsch \& Tromp 2002a), using the same seismic events as the earthquake data described in section 2.1. The time integration of the viscoelastic wave equation on the full globe is tackled using a high-order spectral element method in space and a second-order time difference scheme. Very accurate and perfectly scalable on parallel computers, this method has a long success history in modelling seismic wave propagation (e.g. Padovani et al. 1994; Fichtner et al. 2009; Peter et al. 2011; Cupillard et al. 2012). The 3-D earth model used contains all main global discontinuities included in PREM (Dziewonski \& Anderson 1981) and the recent 3-D $S$-velocity mantle model from Ritsema et al. (2011). Attenuation (PREM) was included. The $P$-velocity profile in the model was obtained applying a depth dependent scaling factor to the $S$-velocity profile. The 3-D crustal structure, which strongly influences surface wave propagation in the period range considered here, was based on the global model CRUST 2.0 (Bassin et al. 2000). Surface topography at the continental scale, load due to oceans, Earth ellipticity and rotation effects were all included in the model. Given the wavelength considered in this study $(>60 \mathrm{~km})$, the effect of crustal and upper mantle structures should be dominant over the other parameters (e.g. local topography) influencing surface wave propagation. Further details on the model and the discretization used can be found in Komatitsch \& Tromp (2002b). The source was a double-couple source with the parameters extracted from the CMT catalogue referenced in Section 2.1 . 
The overall cost of each numerical simulation mainly depends on the desired cut-off period (Komatitsch \& Vilotte 1998; Komatitsch \& Tromp 2002a) and on the seismogram length. To best mimic the earthquake data, we chose a parametrization giving accuracy down to $20 \mathrm{~s}$ period. Owing to the long source-receiver distance and the low velocity at which surface waves propagate, several seismograms have durations of more than $1.5 \mathrm{hr}$. Given that we calculated accurately down to $20 \mathrm{~s}$ period for 289 events, $400000 \mathrm{CPU}$ hours at the CIMENT computing centre of the University of Grenoble were necessary to obtain the synthetic seismograms. Because a numerical Dirac was used as a source time function in the simulations, seismograms were convolved with a band-limited wavelet that filters the trace in the desired frequency band and eliminate numerical noise. A preliminary time-frequency analysis of the seismograms (Levshin et al. 1989) indicated that time-frequency filtering was not necessary, as multiple wave trains were either absent or too close in time to separate through this method. In the absence of noise, it was therefore not necessary to carry out the semi-manual time-frequency filtering that was applied to the earthquake data.

\subsection{Noise correlations}

In the last part of this study, we compare the results from earthquake data with those obtained from noise correlations. The correlation function computed between two continuous records (i.e. ambient seismic noise records) is a good approximation of the Green's function between these two points and can therefore be used for imaging and monitoring applications (Shapiro \& Campillo 2004; Wapenaar 2004; Campillo \& Roux 2014). In other words, the noise correlation functions are equivalent to measure the displacement at one station resulting from a point force excitation located at the other station. The noise correlations are therefore free of complexities of the seismic earthquake source: depth, directivity, and heterogeneous slip in a finite area. We used vertical-vertical correlations because the wavefield in these correlations is dominated by surface (fundamental mode Rayleigh) waves due to the vertical point source. Here we used a data set that has been previously used in Boué et al. (2014) and from which we only extracted the correlation function between the vertical components of a globally distributed seismic network, on one hand, and LAPNET on the other hand. The detailed processing that lead to these correlation functions can be found in Boue et al. (2014). The use of one year of continuous data, and the symmetric part (stack of the positive and negative lag time) of the correlation functions strongly reduced potential bias due to uneven noise source distributions (Froment et al. 2010; Kimman \& Trampert 2010). In total, 593 stations were used (i.e. $39 \times 593$ correlations when combined with LAPNET array), but only approximately one third produced robust surface wave signals in the whole period range we studied. Overall, the signal-to-noise ratio was significantly lower than for the earthquake data. It was not feasible to apply the frequency-time filtering due to significantly variable signal-to-noise ratio in the period interval of interest.

\subsection{Calculation of arrival angles}

We used two different processing methods, a hybrid approach between frequency and time domain beamforming for the earthquake data, and classical $f-k$ analysis for the synthetic seismograms and noise correlations.

The processing for the hybrid method is described in detail in supplementary material of Pedersen et al. (2013) so we only give a brief outline here. For each pair of stations, the time delay was measured as a function of frequency using Wiener filtering. We smoothed the spectra by applying a Gaussian time window on the cross-correlation between the two signals, after which the phase was calculated as the phase of the Fourier transform of the windowed signal. The width of the Gaussian function varied with the target frequency band to ensure that that at least two cycles are present within the part of the window where the amplitude of the Gaussian is higher than 0.5 . The smoothed phase was then transformed to time delays, correcting for phase skips when necessary. This latter step was straightforward as the average phase velocity across the array is well known, and as the lateral variations in lithospheric structure are small. We finally estimated the parameters of the plane wave which best fitted the observed time delays, using the L1 norm. The search explored all combinations of phase velocities within a $2-5 \mathrm{~km} \mathrm{~s}^{-1}$ range $\left(0.01 \mathrm{~km} \mathrm{~s}^{-1}\right.$ steps $)$ and for backazimuths varying within $\pm 30^{\circ}$ of the backazimuth of the great-circle $\left(2^{\circ}\right.$ steps). Our approach is therefore close to the concept of classical frequency-domain beamforming, with some additional constraints, that is high control on the phase smoothing, equal weight to all station pairs and correction for phase skipping, thus minimizing effects of spatial aliasing. The use of the L1 norm, that is the average absolute difference between the observed and predicted delays, strongly reduced the influence of outliers. The L1 norm was subsequently used as a quality indication of the measurements. The processing by Pedersen et al. (2013) indicated that the average phase velocity over all the events was stable below $150 \mathrm{~s}$ period. We therefore limited our analysis, for which we use individual events, to periods of $20-100 \mathrm{~s}$.

We carried out a simple uncertainty analysis for a wave incoming from the north. For each theoretical time delay, random errors were added for which the average absolute error was a given value, which corresponds to the L1 norm cited above. We then calculated the incoming backazimuth for the best fitting wave to these noisy time delays. We repeated this procedure 100 times for any given choice of the L1 norm. As an example, with an L1 norm of $5 \mathrm{~s}$, the error in backazimuth is on average $0.3^{\circ}$ with a standard deviation of $0.4^{\circ}$. These values double if the L1 norm of the data error doubles. As field data have gaps, instrumental problems and occasionally poor signal-to-noise ratio, the real number of stations for which data is used in the analysis is always less than 39. If the number of stations is reduced to 20 through a random selection of stations, the average absolute error is $0.6^{\circ}$ and the standard deviation $0.7^{\circ}$ in the case of a $5 \mathrm{~s} \mathrm{~L} 1$ norm of the error. A conservative estimate is therefore that if all events have an L1 norm less than $5 \mathrm{~s}$, the measurement error is generally less than $1^{\circ}$.

If a geographical subset of the array is chosen, the results deteriorate. The main reason is that the largest distances in the array have strong impact on the estimate of the slope of the best fitting line. For example, when the northernmost half of the array was used, the absolute error increased to $1.9^{\circ}$ and the standard deviation to $1.5^{\circ}$. We therefore use the whole array for the data analysis for all periods.

While the hybrid beamforming was well adapted to the earthquake data, it was not adapted to the noise correlations as the frequency smoothing used is not well adapted to a narrow frequency band. We therefore applied classical $f-k$ analysis on this data sets. A basic 'delay and sum' plane wave projection was performed on the data set in the frequency domain (Rost \& Thomas 2002) and spectral smoothing was achieved by averaging over very narrow period interval ( $\pm 5 \mathrm{~s}$ around the target period). The best-fitting plane waves, that is associated with the maximum beam amplitude, was 


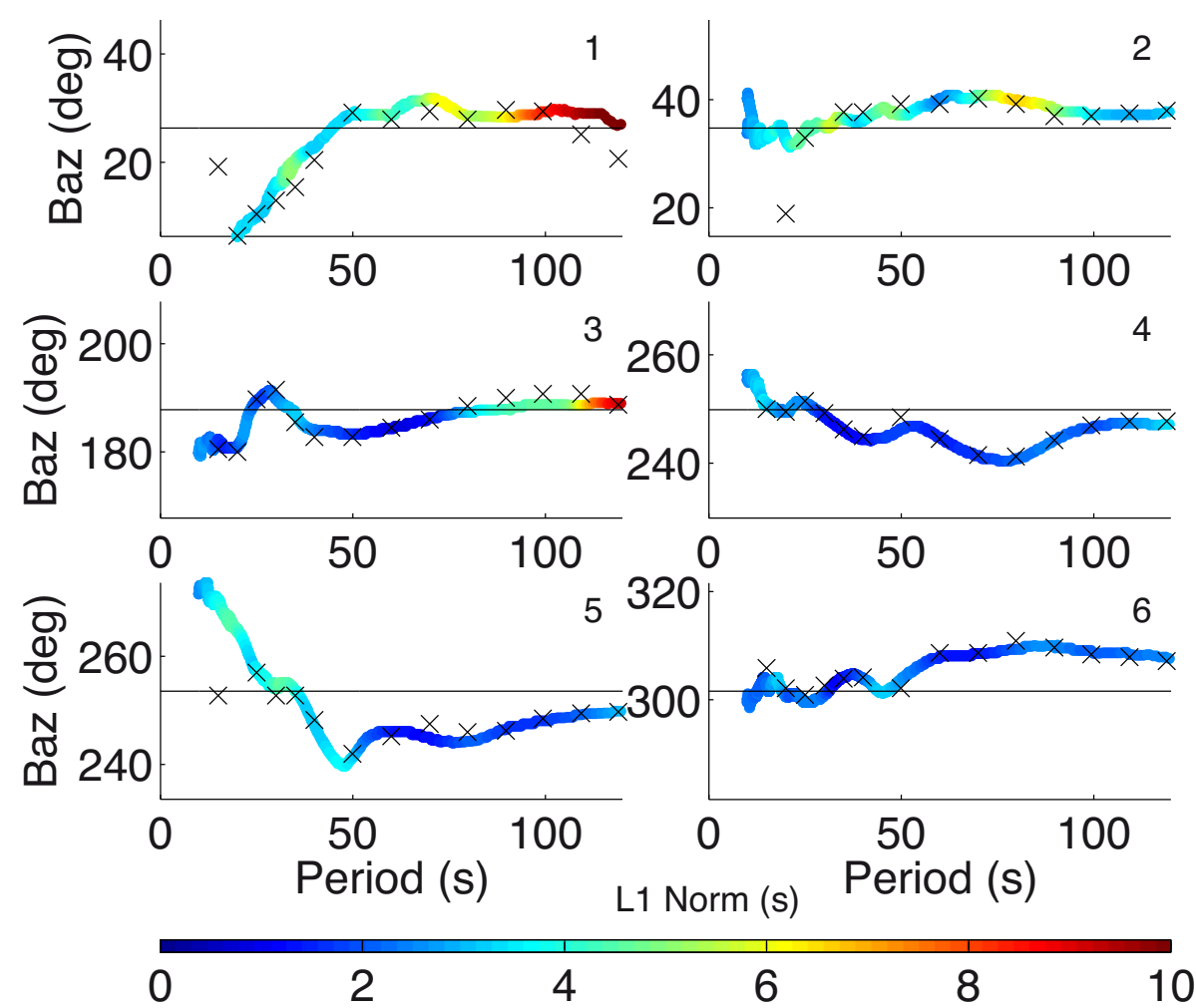

Figure 2. Observed backazimuth of fundamental mode Rayleigh waves recorded by the LAPNET/POLENET array for the events 1-6 (indicated in the top right of each plot) depicted in Fig. 1. The L1 norm of the fit of predicted delays across the array with the observed delays is shown by the colour scale, and can be used as a proxy for the quality of the observation. The backazimuth corresponding to great-circle propagation to the centre of the LAPNET array is shown by a solid line, and the $y$-axis is showed within $\pm 20^{\circ}$ around this angle. The crosses show $f-k$ beamforming for the same events and periods.

identified within a search area defined by slowness up to $0.35 \mathrm{~s} \mathrm{~km}^{-1}$ with steps of $0.005 \mathrm{~s} \mathrm{~km}^{-1}$ and a backazimuth range of $\left[-25^{\circ} ; 25^{\circ}\right]$ around the theoretical backazimuth with steps of $0.25^{\circ}$. This analysis could only be carried out for periods longer than $20 \mathrm{~s}$, due to spatial aliasing.

To ensure coherency between the two methods, we compared the output of them for all the seismic events. Fig. 2 shows the comparison for a few selected events. Overall, both methods yield quite similar results when the signal-to-noise ratio is high even though the spectral smoothing is somewhat more efficient in the hybrid method. We additionally verified that deviations measured by the two methods are within $1^{\circ}$ on the synthetic seismograms.

\section{RESULTS}

\subsection{Global scale}

In this section we first present a few examples for individual events (numbered 1-6 in Fig. 1), followed by an overview of the results for all the events.

Fig. 2 shows the variation in backazimuth with period for the six events highlighted in Fig. 1. Events 1 and 2, of similar depth but different focal mechanisms, are located so that the theoretical backazimuths predicted at the centre of the array for these events are close $\left(27^{\circ}\right.$ and $\left.35^{\circ}\right)$. Events 4 and 5 occurred at almost the same location, only $400 \mathrm{~km}$ apart (epicentral distances are respectively 8041 and $7989 \mathrm{~km})$, at the same depth (10 and $9 \mathrm{~km})$ and with very similar focal mechanisms. From here on, the term deviation is used for the difference between observed backazimuth at the network and that of the great-circle between the event and the centre of the array. Positive numbers correspond to clockwise deviations of observed backazimuth at the array as compared to the great-circle reference.

Fig. 2 demonstrates that the deviations vary strongly with period (including sign changes). This variation with period indicates that it is difficult to correctly integrate observations of deviations obtained by polarization measurements into tomography schemes, as the frequency resolution is limited in the case of single station measurement. The deviations may reach values of more than $20^{\circ}$, being particularly strong at short period, that is for periods where the waves are particularly sensitive to the laterally varying crustal structure. At longer period the deviation is smaller, yet not negligible, as illustrated by events 4-6. A second observation is that, in agreement with Foster et al. (2014a), events in approximately the same location and with similar source mechanisms have quite similar deviations at long periods. At short periods the deviations may still be quite different, as illustrated by events 4 and 5 which have deviations with approximately $15^{\circ}$ difference at $20 \mathrm{~s}$ period. Consequently it is not straightforward to use deviations from one event as a proxy for another, at least at short periods. The difference between events further apart is significant: while short-period waves from event 1 are strongly deviated to the north (exceeding the $20^{\circ}$ scale of Fig. 2), waves in a similar period interval from event 2 show a backazimuth close to the great-circle.

Notably, the average absolute deviations are still significant $\left(3^{\circ}-4^{\circ}\right)$ at long periods. This result is confirmed by Fig. 3 which shows the mean absolute deviation as a function of period. One explanation could be that we have reached the noise level: as we calculate the average over the absolute deviations, this average cannot go to zero in the presence of noise. The examples of Fig. 2 


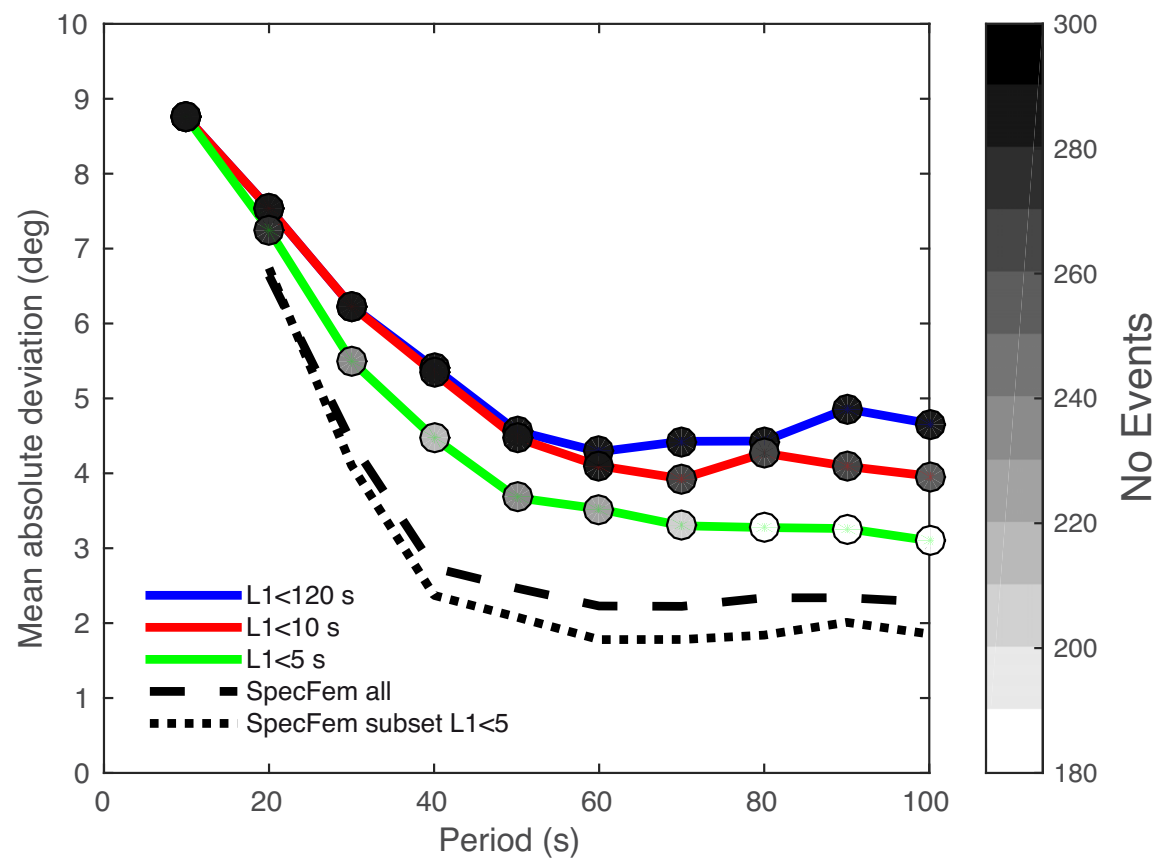

Figure 3. Mean absolute deviation as a function of period. For each period, data points corresponding to the L1 norm smaller than a given limit are shown. Blue line: No selection on the L1 norm. Red line: L1 norm smaller than $10 \mathrm{~s}$. Green line: L1 norm smaller than $5 \mathrm{~s}$. The grey scale of the points corresponds to the number of events over which the average is calculated. The black dashed line shows the mean absolute deviation measured on all the synthetic seismograms while the black dotted line shows the mean absolute deviation measured on the synthetic seismograms for the earthquake data selected using the L1 $<5 \mathrm{~s}$ criteria.

are however a first indication that we are not only measuring noise at long period, as we see spatial coherency at long periods, which will be further discussed in Section 3.2. This finding does not depend on the presence of outliers, as different quality criteria yield essentially the same result: Fig. 3 shows three different average curves, based on increasing levels of quality selection (based on the L1 norm of the measurement, see Section 2.4) of the events that contribute to the average. The choice of the L1 fit of $5 \mathrm{~s}$ (or $10 \mathrm{~s}$ ) will have no effect at $10 \mathrm{~s}$ period (or $20 \mathrm{~s}$ period), as the correction for phase skips will ensure that data points are within half a period of the time delays predicted using the average propagation velocity in the area. Even though the deviation is slightly lower, by approximately $1^{\circ}$, for the stricter quality criterion, all the preliminary conclusions of the above section hold. There is a compromise between the quality criterion (L1 norm selection) and the number of events available for the statistics (grey scale). In the subsequent part of this section, and to be coherent with the geographical analysis in the following subsection, we only use events and frequencies where the L1 norm is better than $5 \mathrm{~s}$, but we verified that the conclusions remain the same if we loosen the criterion on the L1 norm to $10 \mathrm{~s}$.

Fig. 3 also shows the deviations using the synthetic seismograms (see Section 2.2). We calculated the average over all 289 events and over the subset of events that correspond to $\mathrm{L} 1<5 \mathrm{~s}$ for the LAPNET data. The general trend between numerical simulations and earthquake data are very similar, however the synthetic seismograms underestimate the deviations by $1^{\circ}-2^{\circ}$, or $10-40$ per cent, as compared to the curve based on a quality criteria L1 $<5$ s. Surprisingly, the average absolute deviations are less underestimated at short periods than at long periods, in spite of the global models being less likely to be adequate at short periods. The good agreement at short periods does however not hold for deviations from individual events, as discussed in Section 3.2.
To better understand the deviations that lie behind the averages presented above, Fig. 4 shows the spread of deviations (in $4^{\circ}$ bins), for deviations measured on earthquake data and synthetic seismograms, for selected periods between 20 and $100 \mathrm{~s}$ period. In this figure, we use the same events (based on the L1 $<5 \mathrm{~s}$ criterion) for earthquake data and numerical simulations. For the earthquake data we observe a smooth distribution with a peak at $0^{\circ}$ deviation, with no indication that the averages presented in Fig. 3 would be strongly influenced by outliers. The distribution is however slightly skewed at intermediate periods, and at $40 \mathrm{~s}$ period in particular, reflecting the uneven distribution of seismic events rather than a random distribution of measurement errors. The asymmetry is likely to be linked to the earthquake distribution as compared to the LAPNET array, as some source regions are strongly represented in the histograms. On the other hand, as seen in Fig. 2, even earthquakes located relatively close together may have different deviations, which means that at least some large-scale propagation effects must influence the results, such as variations in crustal and/or lithospheric thickness. For example $30 \mathrm{~s}$ surface waves propagate faster in oceanic than in continental lithosphere due to thinner crust, while the opposite is true at $100 \mathrm{~s}$ due to fast shear-velocities in thick lithosphere in large areas of the continents.

Deviations are expected to increase with epicentral distance, and some surface wave tomographies based on the great-circle approximation therefore limit the data selection to relatively short epicentral distances (e.g. Debayle et al. 2005). Fig. 5 shows the deviations as a function of distance for the same periods as the ones used in Fig. 4. It is noticeable that at short periods, the deviations may be as large as $10^{\circ}$ even at the shortest epicentral distances $\left(\sim 25^{\circ}\right.$ distance), but intermediate periods also have relatively high deviations (up to $10^{\circ}$ ) at distances of $50^{\circ}-100^{\circ}$, and increasing further with longer distances. The figure also shows that the strong deviations observed on synthetic seismograms are dominated by the longest distances, 

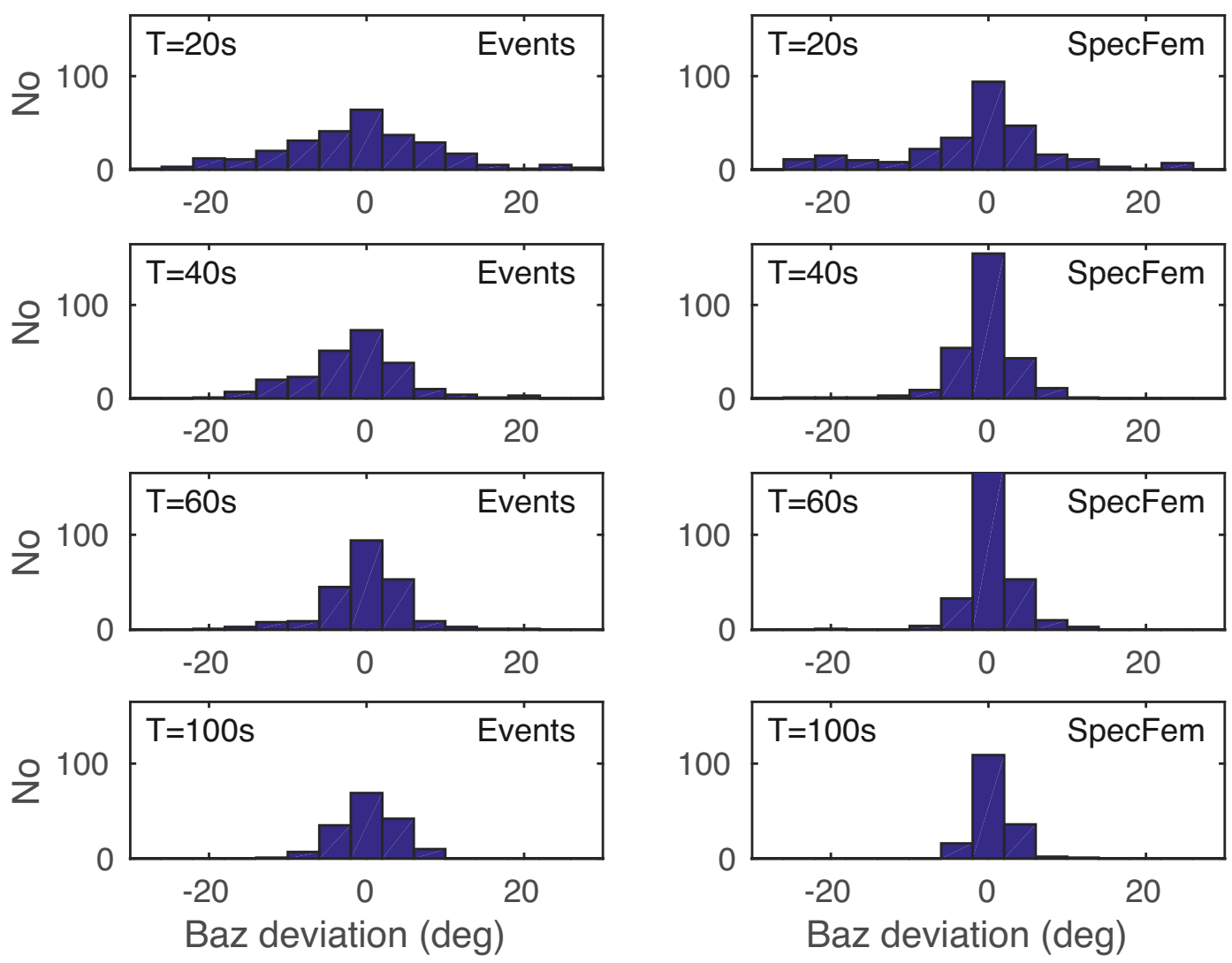

Figure 4. Histograms of number of events in $4^{\circ}$ bins and for 4 different periods ranging from $20 \mathrm{~s}$ (top left-hand panel) to $100 \mathrm{~s}$ (bottom). The left-hand column shows the deviations for the field data described in section 2.1 (using the $\mathrm{L} 1<5 \mathrm{~s}$ criterion), the right-hand column for synthetic seismograms described in Section 2.2, using the same events as for the left-hand column. The number of events for SPECFEM3D is slightly higher than the maximum scale at $60 \mathrm{~s}$ period; this saturation is chosen to correctly visualize the data at 20 s period.

with a few exceptional outliers. An exception is 20 s period where the deviation dependency on distance is qualitatively similar for the two data sets.

Fig. 6 shows the comparison of deviations observed for each earthquake with those obtained from the equivalent synthetic seismograms, for four selected periods (note change of scale between $20 \mathrm{~s} / 40 \mathrm{~s}$ plots and $60 \mathrm{~s} / 100 \mathrm{~s}$ plots). While the best fitting lines all have positive slopes $(0.4$ at $20 \mathrm{~s}, 0.2$ at $40 \mathrm{~s}, 0.2$ at $60 \mathrm{~s}$ and 0.35 at $100 \mathrm{~s})$, the variance reduction as compared to great-circle propagation is better at long periods than at short periods $(16,11$, 18 and 28 per cent). This indicates that numerical simulations at long periods can be used to estimate deviations, but they will be underestimated (see also Fig. 3), and that individual predictions may have significant errors. Such estimates may however still better than assuming, for example, great-circle propagation. As expected, these results show that global mantle models may be overdamped or oversmoothed as compared to reality, but all the main features are captured. On the contrary, at short periods, the simulations cannot be used for any predictions of deviations. Two problems may contribute. The resolution of crust 2.0 is probably not sufficient, as the cell size is approximately 3-4 wavelengths of the shortest period surface waves of this study. Secondly, and possibly more importantly, the fine structure of the crust is unknown in many areas, even first-order features such as crustal thickness. So not only the model is too smooth, but it may be inaccurate in many places. The present effort of the seismological community to install and operate largescale seismic networks, in combination with the detailed crustal tomography offered by Ambient Noise Tomography (Shapiro \&
Campillo 2004) will provide significant progress over the next decade, and the efforts of updating global crustal models should be pursued (e.g. crust1.0 at http://igppweb.ucsd.edu/ gabi/rem.html).

\subsection{Geographical distribution of deviations}

While the previous section focused on the statistics of the observations, in the present section we will focus on systematic variations across geographic areas. In this subsection, at each period we again show the results only for earthquakes where the L1 norm is smaller than $5 \mathrm{~s}$.

Fig. 7 shows the global distribution of deviations at 60 and 100 $\mathrm{s}$ period. The first observation is that, even though individual data points should be treated with care, there are coherent deviations across large geographic areas at these intermediate to long periods. For example, there is a systematic change between negative deviations along the west coast of South America to positive deviations for surface waves emitted from earthquakes on the south west coast of the North American continent. Other areas with systematic patterns visible at a global scale are strong positive deviations between Indonesia and the Himalayas and in the Fiji region, as well as across the east-west trending set of events in the central and southern Atlantic Ocean. This spatial coherency at large scale and long periods indicate that deviations remain significant at long period (in reference to the discussion on Fig. 3, Section 3.1). The largescale features are, as expected from Fig. 6, overall well captured by the numerical simulations (all events shown) even though the 

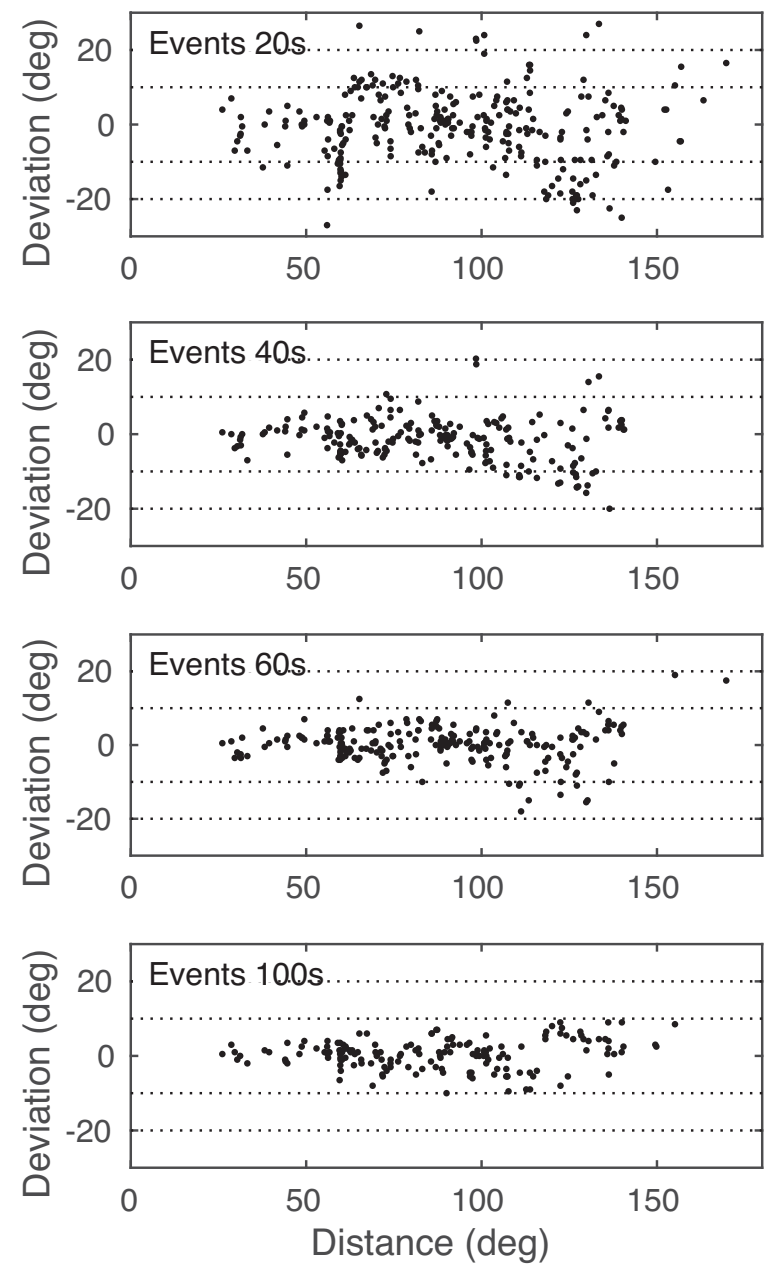
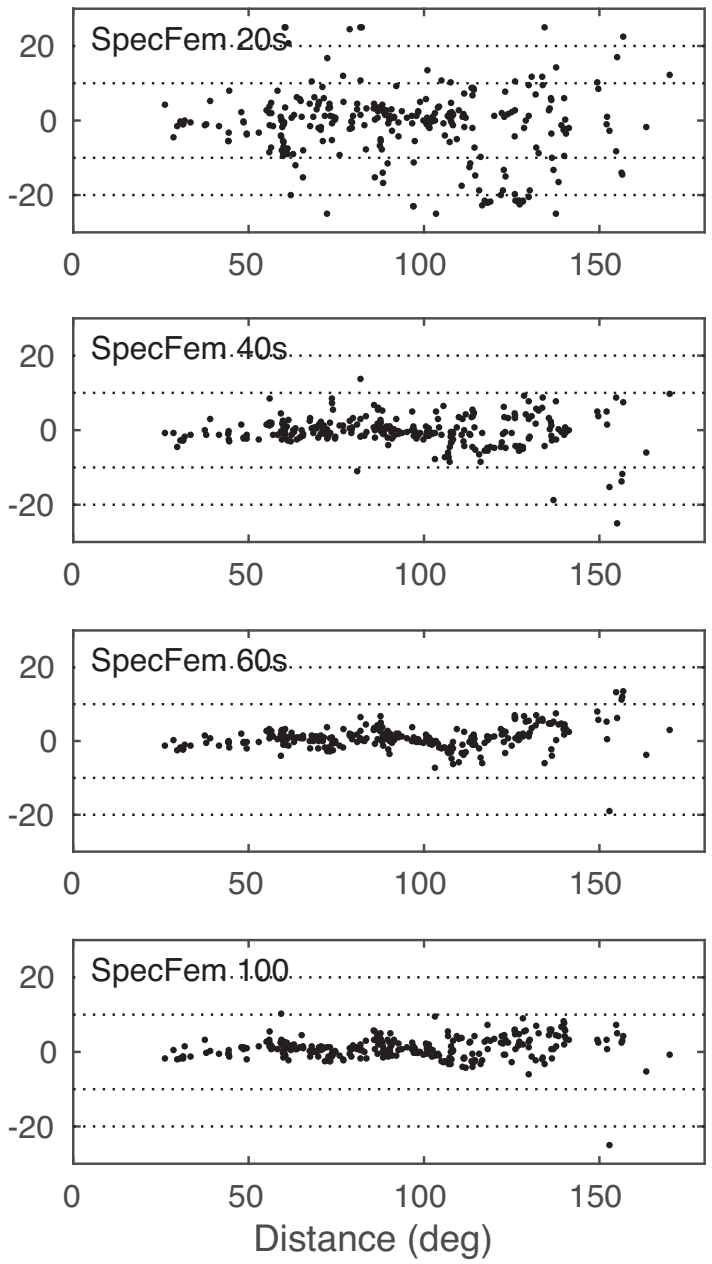

Figure 5. Deviations (observed backazimuth - great-circle backazimuth) as a function of epicentral distance for periods between $20 \mathrm{~s}$ (top) and $100 \mathrm{~s}$ (bottom). Event data (selected using $\mathrm{L} 1<5 \mathrm{~s}$ ) as described in Section 2.1: left-hand column. Numerical simulations, as described in Section 2.2: right-hand column. For easy reading, $10^{\circ}$ and $20^{\circ}$ deviation are shown as dotted lines.

amplitudes are smaller and there are significant differences for some of the events.

At short periods the spatial patterns vary too rapidly to identify in a world map view, with the exception of events from the Aleutian and Kurile Islands that are significantly deviated (up to $-22^{\circ}$ at 20 s period, see Fig. 10) in spite of the moderate distances of these events to the LAPNET array. The deviations for events in that area are negative up to $80 \mathrm{~s}$, after which they become positive $(+2$ to $+5^{\circ}$, as seen in Fig. 7).

An illustrative example of complex regional variations of deviations is provided in Fig. 8, which shows a zoom-in on the area of Papua New Guinea and Solomon Islands, for periods between 20 and $100 \mathrm{~s}$, using earthquake data and synthetic seismograms. This area happens to be one where the pattern of deviations observed on earthquake data is fairly well mimicked by the numerical simulations, thereby providing insights into the significant changes of deviation for closely located events. Towards the southeast of the area, deviations are strongly negative at short periods, changing to strongly positive at $80 \mathrm{~s}$ period, after which the deviations remain positive but with a reduced amplitude. At the northwest end of the area positive deviations dominate at $20 \mathrm{~s}$ period, but the scatter between observed data is large. Already at $40 \mathrm{~s}$ period, and fully clear at $60 \mathrm{~s}$ (and $80 \mathrm{~s}$ ) period, the two western branches show deviations that are of opposite sign, despite being located only a few hundreds of kilometres apart and approximately $12000 \mathrm{~km}$ from the LAPNET array. The waves from the southern branch that propagate towards LAPNET cross the northern branch, so using earthquake data alone it is not straightforward to explain this different pattern by propagation at a large scale between the source and LAPNET.

Interestingly, the difference between the northern and southern branch are well accounted for by the numerical simulations at $40 \mathrm{~s}$, so we further analysed each $f-k$ beamforming of the synthetic seismograms to better understand the observations, as we fully control all parameters of the simulation. Different source mechanisms do not explain the spatial variability (see Fig. S2). In the cases where the two earthquake epicentres are almost colocated but the deviations are significantly different, the earthquakes are located at different depths. In fact, almost all the earthquakes of this area emit surface waves that once impinging upon the LAPNET array are constituted by two wave trains. Sudden jumps in deviations correspond to changes of relative amplitudes between the two spots in the $f-k$ domain. These two wave trains arrive for all practical purposes at the same time at the LAPNET array and cannot be identified through time-frequencies analysis. A systematic inspection revealed that the majority of the 289 events have this type of multipathing at $20 \mathrm{~s}$ period, and many events also have multipathing at longer periods (40 s). This phenomenon unsurprisingly increases with distance, but is already common at standard distance ranges for teleseismic 

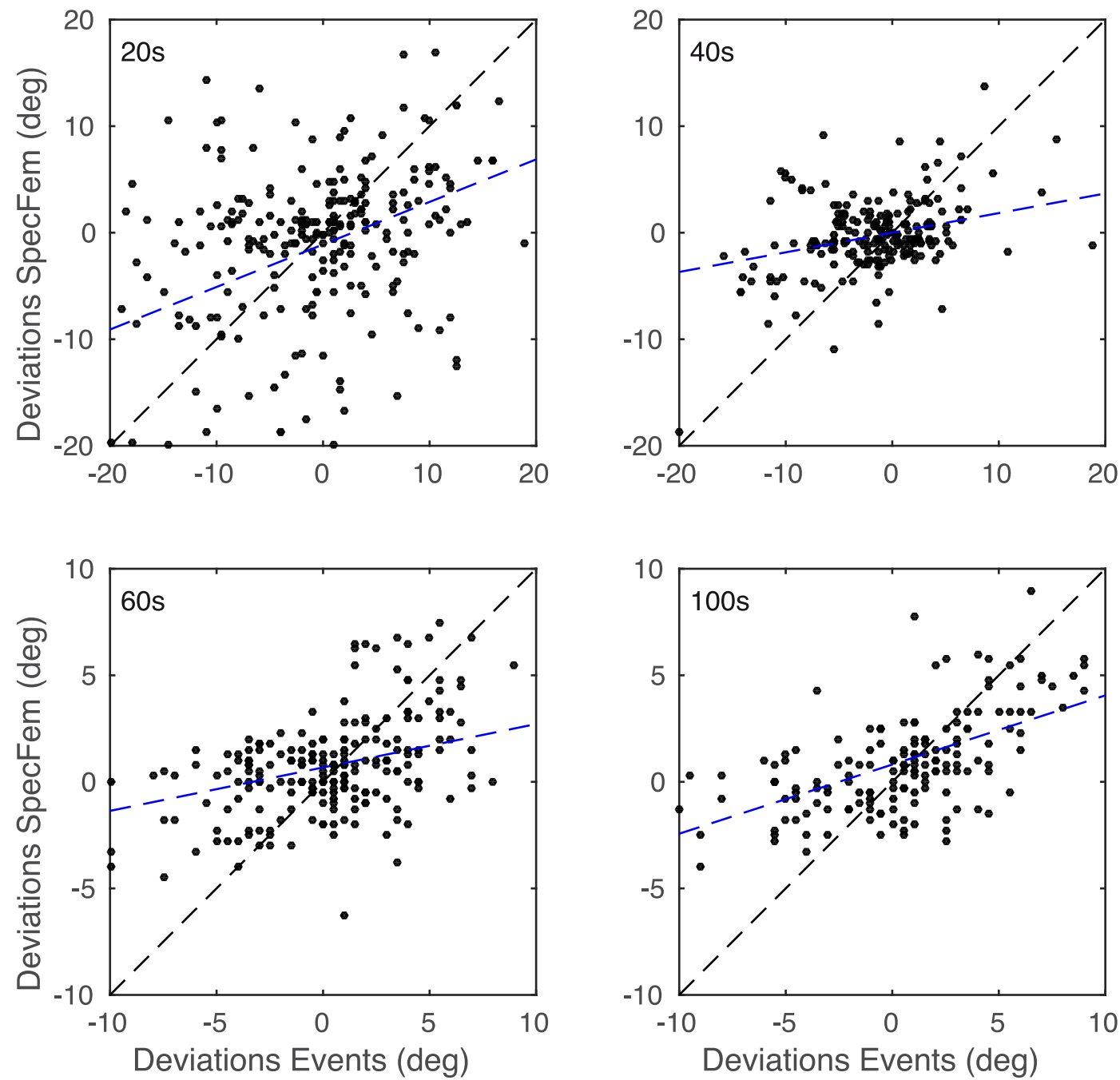

Figure 6. Comparison between deviations in degrees observed for Earthquakes ('Events') and numerical simulations ('Specfem') at the periods marked in the top left-hand corner of each plot. The line $y=x$ (i.e. deviations measured on field data and synthetic seismograms being exactly equal), is shown by the black dashed line, while the best-fitting line is shown by the blue dashed line.

surface wave tomography and two-station measurements. The difference in relative amplitude of two wave trains explains the differences between the two branches in the northwestern part of the area shown in Fig. 8, and explains the abrupt changes for earthquakes that are located close together. The issue of multipathing may have been somewhat underestimated until now, as most surface wave studies are based on the assumption that frequency-time filtering minimizes the problem.

The term multipathing may even be slightly misleading, as it is often used to describe late arrivals associated with deterministic and late reflected and refracted waves. As the waves arrive approximately simultaneously, and as waveform healing partly masks the effect of scattering, it may be more adequate to describe them as a complex and non-plane wave front resulting from multiple scattering and refraction/diffraction. Several groups have proposed surface wave tomography methods that take into account non-plane incoming waves (e.g. Friederich \& Wielandt 1995; Bruneton et al. 2002; Chevrot \& Zhao 2007; Lin \& Ritzwoller 2011; Salaün et al. 2012). Li et al. (2003) specifically assumed that the incoming wave field can be adequately approximated by a sum of two incident waves, an assumption which according to our results seems to be adequate at $20-40 \mathrm{~s}$ period in many cases. Also, averaging over many events may mitigate the problem when phase velocities are calculated between two seismic stations (Pedersen 2006).

\subsection{Comparison with noise correlations}

The agreement between earthquake data and numerical simulations at short period is, in spite of some exceptions (see Fig. 6) overall poor, as discussed in Section 3.1. A possible complement to the simulations is therefore to study deviations of surface waves extracted from seismic noise correlation, with the limitations that earthquakes and seismic stations are generally not colocated, and that the source term is different in the two cases. Indeed the noise correlations (vertical-vertical component) will extract surface waves as emitted by a vertical point force at the surface, in contrast with the extended earthquake sources at depth. The practical limitation is that the signal-to-noise ratio of the correlations (and therefore the beam) is very variable. Some networks, such as F-NET and USArray which are located at only $\sim 70^{\circ}$ distance to LAPNET, produced very high quality correlations and high quality beams, while others were of poorer quality, whether due to metadata or installation issues, or characteristics of the seismic noise. We finally chose to use, at each 


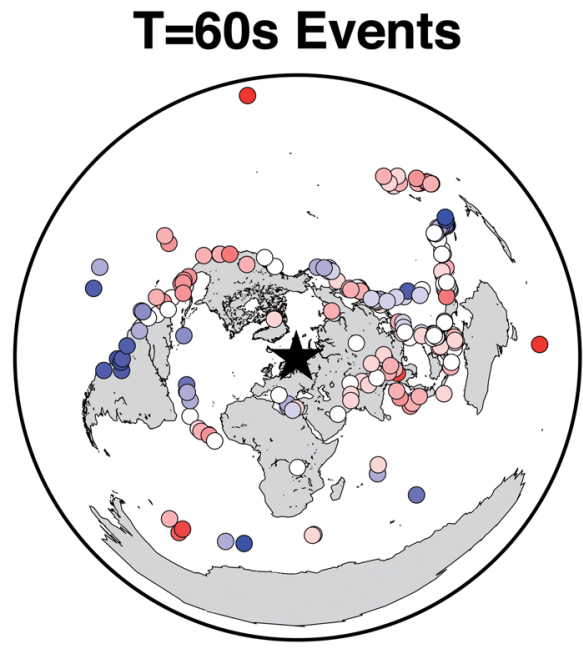

\section{$\mathrm{T}=60$ s SpecFem}

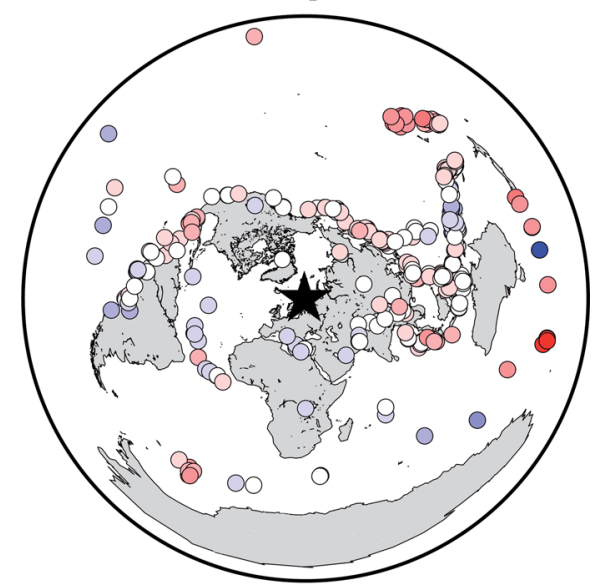

\section{$T=100$ s Events}
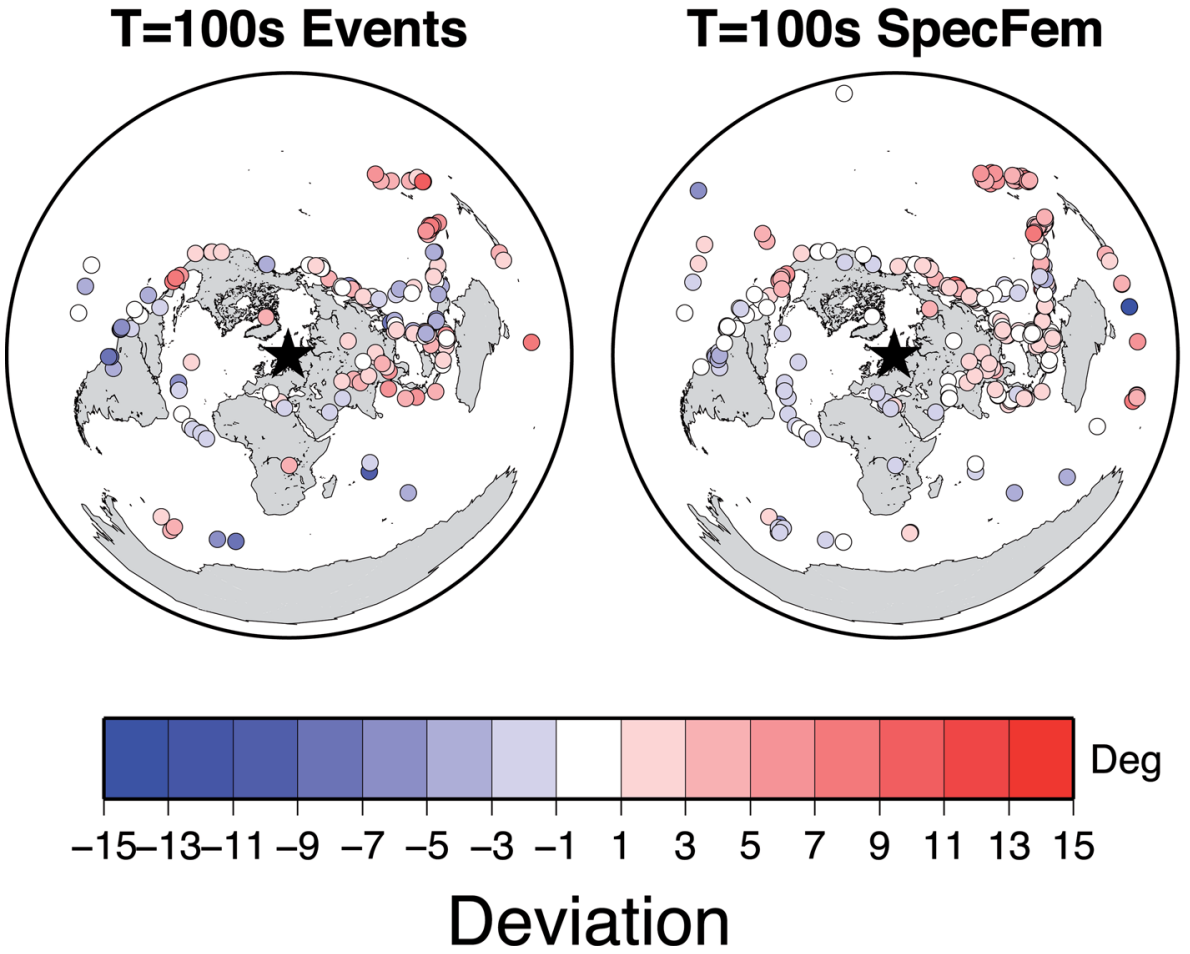

Deg

Figure 7. Observed deviations for events across the globe (same projection as Fig. 2), for $60 \mathrm{~s} \mathrm{(top)} \mathrm{and} 100 \mathrm{~s}$ (bottom) period. Results from earthquake data are shown in the left-hand column, while results from numerical simulations are shown in the right-hand column.

period, the 10 per cent of the stations that have the highest beam stack.

Fig. 9 shows the deviations observed on the noise correlations as a function of those obtained from earthquake data, for event-station pairs that are located within $2^{\circ}$ distance. The comparison shows overall a better agreement between the two data sets than between events and numerical simulations. The best agreement is at short ( 20 and $30 \mathrm{~s}$ ) period where the signal-to-noise ratio of the correlation is the highest, while the fit to the line is poor at $40 \mathrm{~s}$ period and fairly good at $60 \mathrm{~s}$. The strong variability in quality may be related to the uneven coherency of the ambient noise wave field due to the variability of ocean-crust interactions in the Microseisms-Hum frequency range (Traer \& Gerstoft 2014; Ardhuin et al. 2015). As the number of data points is low, linear regression may not be meaningful, and the best-fitting line is therefore not added in the plots. Within the limitation of the small number of data points, the best-fitting slopes are $1.0(20 \mathrm{~s}), 0.4(30 \mathrm{~s}), 0.3$ (40 s) and $0.8(60 \mathrm{~s})$ with variance reduction of $83,10,42$ and 41 per cent as compared to a slope of 0 . The variance reduction for the best-fitting line as compared with numerical simulations (see discussion associated with Fig. 6), is twice as good at $60 \mathrm{~s}$ period, four times better at $40 \mathrm{~s}$ period and five times better at $20 \mathrm{~s}$ period.

With this comparison in mind, Fig. 10 shows the earthquake and the noise deviations plotted on the same map. For clarity, we have used a Mercator projection and limited to a large area around the Pacific Ocean, as the number of earthquakes located close to seismic stations of the global noise data set outside these regions is very small. 

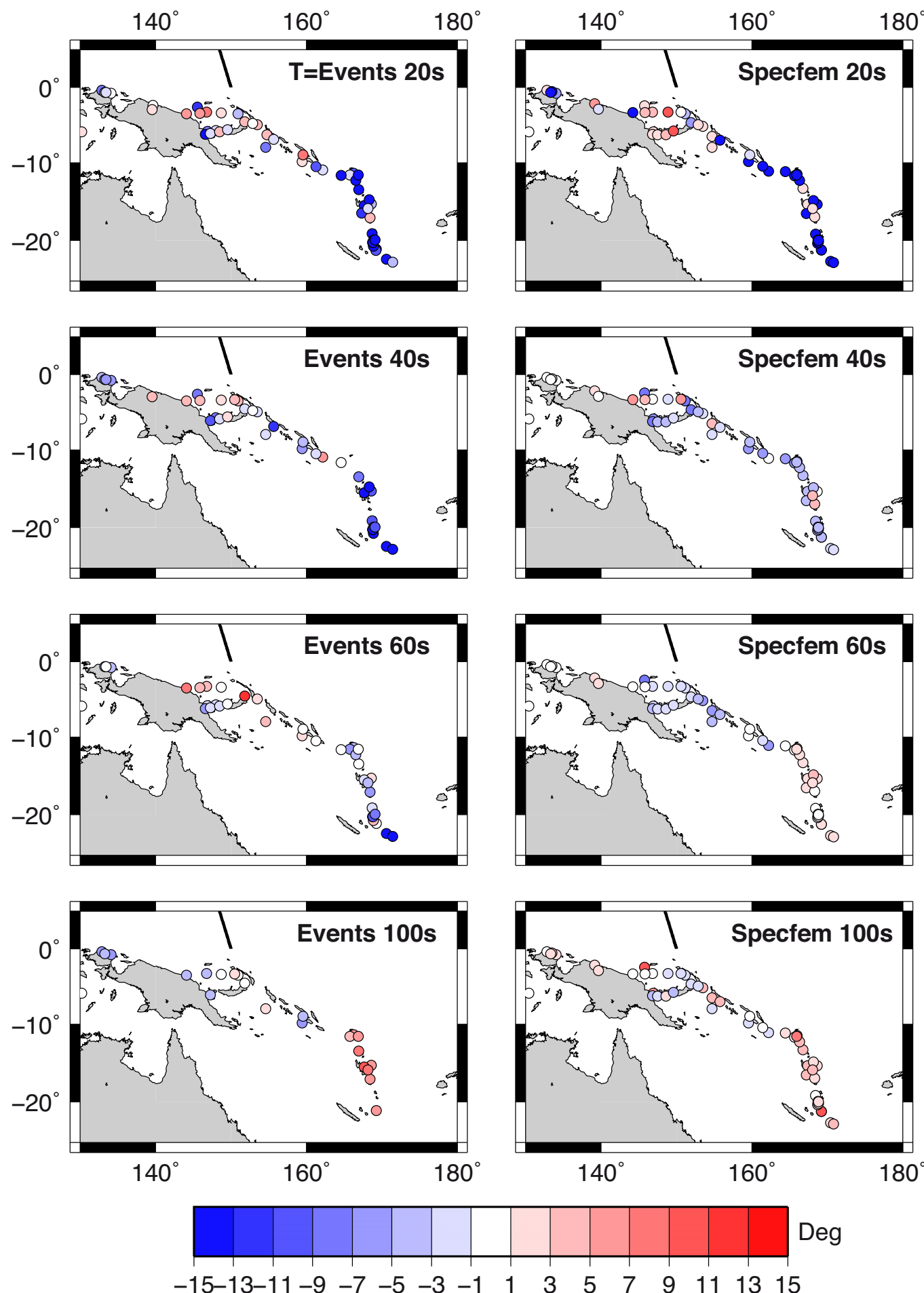

Deviation

Figure 8. Zoom-in on the region around Papua New Guinea and Solomon Islands for periods between $20 \mathrm{~s}$ (top panel) and $100 \mathrm{~s}$ (bottom panel), for earthquake data (left-hand panel) and synthetic seismograms (right-hand panel). The azimuth towards the centre of LAPNET is shown as a black line at the top of each plot.

Especially at $20 \mathrm{~s}$ period, the agreement is convincing, despite some scatter in both data sets. In particular, both data sets show a change from negative deviations across the Aleutian Islands and Kurile Islands to positive deviations in the Japanese main islands. Despite the apparently poorer fit between earthquake and noise data at longer periods, there are several good fits and no obvious largescale inconsistencies.

Fig. 11 shows a zoom-in area, which is particularly interesting for the comparison, as the dense F-net array is of very high quality, and located in an area of many seismic events, 

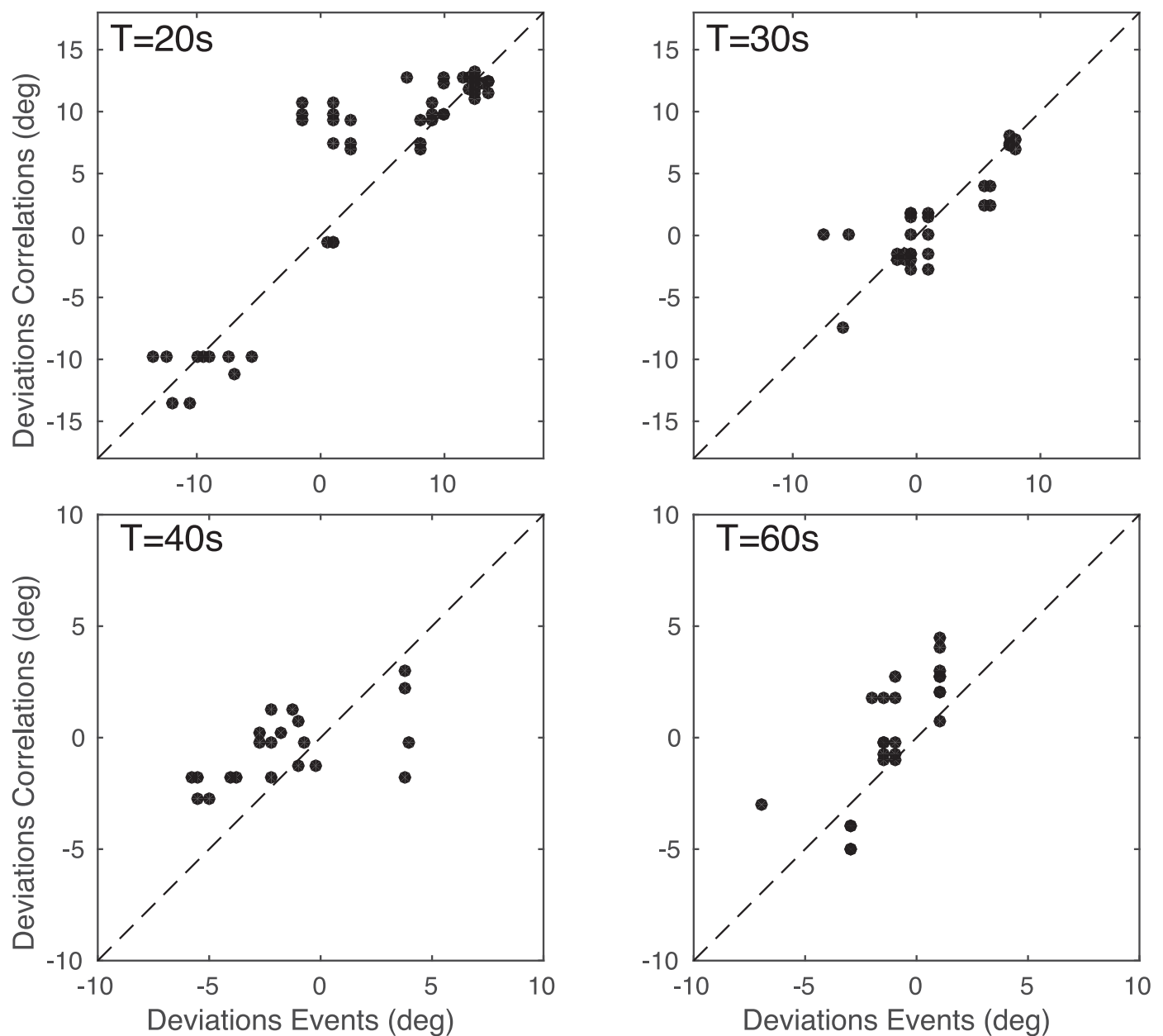

Figure 9. Observed deviations for earthquakes (horizontal axis) and noise correlations (vertical axis) for periods of $20 \mathrm{~s}$ (top left-hand panel), $30 \mathrm{~s}$ (top right-hand panel), $40 \mathrm{~s}$ (bottom left-hand panel) and $60 \mathrm{~s}$ (bottom right-hand panel). The data points depicted are those for which a seismic station used for the correlation is located less than $2^{\circ}$ from the earthquake. The line $y=x$ (i.e. deviations measured on field data and correlations being exactly equal) is shown as a dashed line.

almost all with compressional focal mechanisms according to the Hi-net focal mechanism catalogue (http://www.hinet.bosai. go.jp/AQUA/aqua_catalogue.php?). The change of deviations with period is significant, with strong positive deviations across all of Japan at $20 \mathrm{~s}$ period and a change to (slightly) negative deviations across most of Japan at $30 \mathrm{~s}$ and above. The deviations remain positive, with decreasing amplitude, in the south, with a very abrupt transition between the two areas. The agreement between earthquake and noise data is striking at 20-40 s period, while the number of data points is small at $60 \mathrm{~s}$ period. The agreement at $20-40 \mathrm{~s}$ period indicates that source radiation pattern is in the case of Japan not a significant contribution to the lateral variations in deviations, while Earth structure must play a major role.

\section{CONCLUSIONS AND DISCUSSION}

The first objective of this work was to provide quantitative input for surface wave tomographies which potentially rely on the greatcircle approximation. The study was made possible through the availability of data from a dense broadband array in northern Finland, which is located in an area with only small lateral velocity variations in the crust and upper mantle. Observed variability in great-circle deviations can therefore be mainly attributed to largescale propagation effects rather than to heterogeneities in the receiver region.

At short periods (20 s), the deviations are routinely $10^{\circ}$, and can be significantly higher. The error on phase velocities obtained from two-station measurements can be predicted by simple geometric considerations (see Fig. S3). Even though the error on local phase velocities measured by two-station methods can be reduced by averaging over several earthquakes, the deviations are likely to imply a systematic overevaluation of velocities. Network design can at least partly accommodate for this difficulty, through correcting the arrival angle using beamforming based on neighbouring stations (Baumont et al. 2002; Bourova et al. 2005; Kaviani et al. 2007; Foster et al. 2014a). Global studies (e.g. Woodhouse \& Wong 1986) would on the contrary tend to have a bias towards lower velocities, depending on the deviation (i.e. period dependent) and the path length. One particular consequence of the very strong deviations at short period is that it may be so large that taking into account finite frequency effects based on kernels or Fresnel zones (e.g. Wang \& Dahlen 1995; Ritzwoller et al. 2002; Yoshizawa \& Kennett 2002; Zhou et al. 2004) around the great-circle may be inadequate. The data from the present study should allow better quantifying and possibly fostering tools to correct for these effects. 


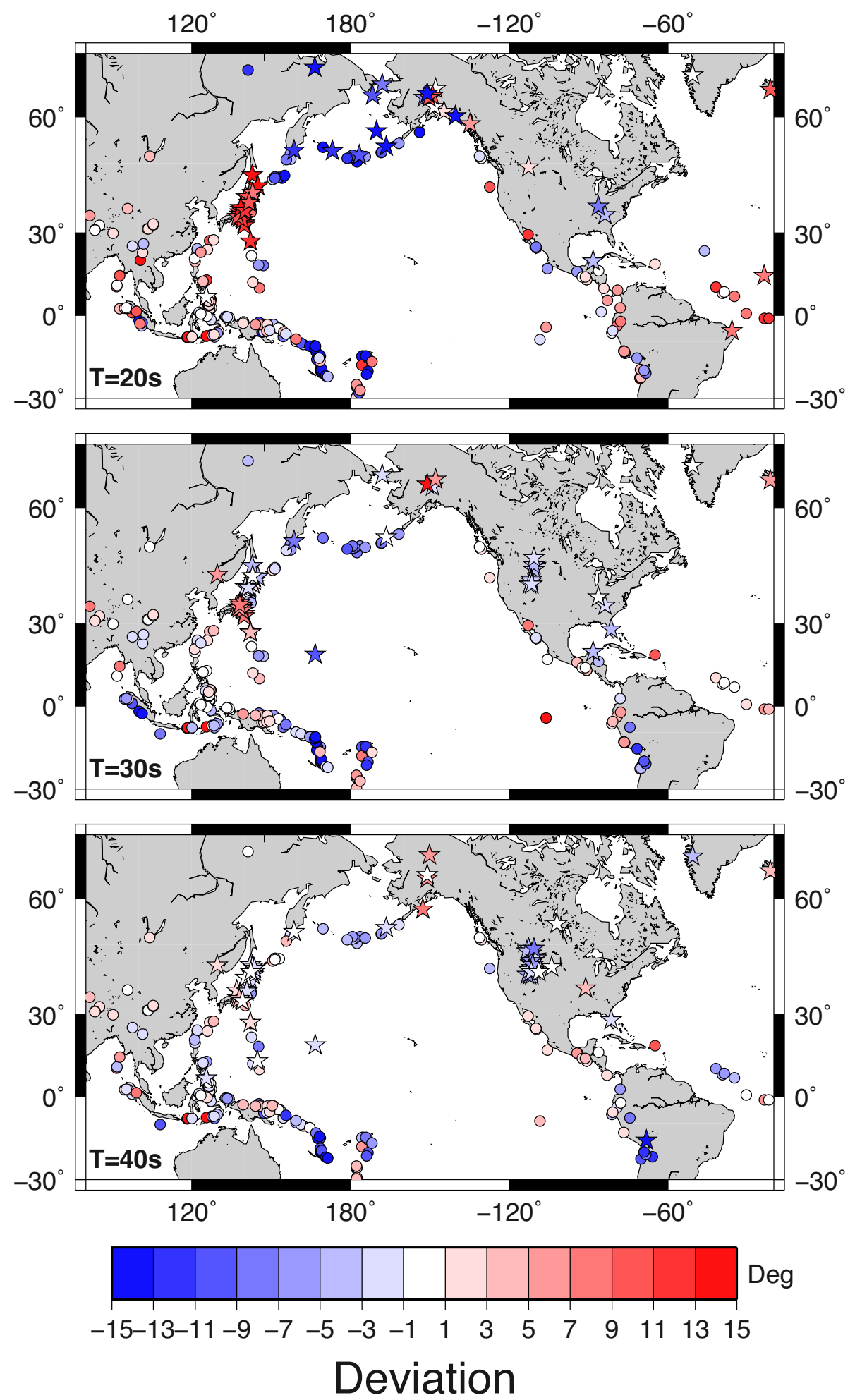

Figure 10. Observed deviations for earthquakes (circles) and noise correlations (stars) for $20 \mathrm{~s}$ (top), $30 \mathrm{~s}$ (centre) and $40 \mathrm{~s}$ (bottom) period.

An additional observation at short period is that multipathing is the norm, rather than the exception, even after frequency-time filtering. Note that in this case multipathing implies waves that arrives almost simultaneously at the array. The observed deviation may therefore change significantly with small changes in earthquake hypocentre, with the change of the relative amplitude of each arrival. The focal mechanism seems to play a secondary role to this effect, therefore we tentatively explain this as the result of diffraction and scattering effects in the area around the source. Our results also indicate that $20-40$ s Rayleigh wave propagation cannot be fully understood within a ray-geometrical framework, even if this approximation leads to robust results in many cases. For our data set, and below $20 \mathrm{~s}$ period, the multipathing becomes very severe, and extreme caution should be taken for phase velocity 

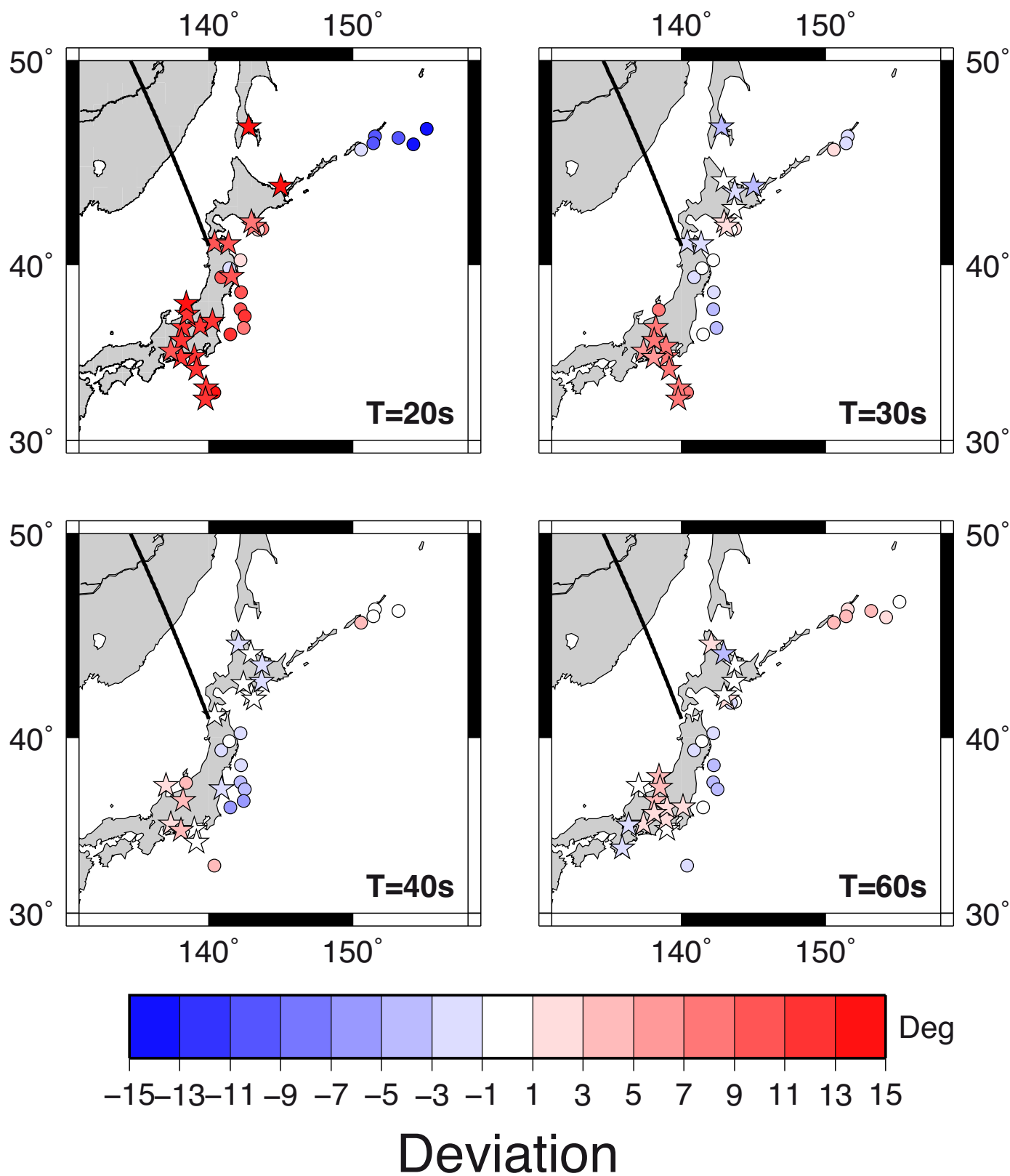

Figure 11. Observed deviations for earthquakes (circles) and noise correlations (stars) in the region of Japan for $20 \mathrm{~s}$ (top left-hand panel), $30 \mathrm{~s}$ (top right-hand panel), $40 \mathrm{~s}$ (bottom left-hand panel) and $60 \mathrm{~s}$ (bottom right-hand panel) period. The azimuth towards the centre of LAPNET is shown as the solid black line.

measurements at teleseismic distances, even when the surface waves appear as a single arrival in the frequency-time domain. Multipathing can be modelled in several ways, either by a discrete sum of waves (e.g. Maupin 2011 for the general case, Pedersen 2006, for an application to seismic surface waves), non-plane wave fronts (Friederich \& Wielandt 1995), or using finite frequency kernels (e.g. Chevrot \& Zhao 2007). In any case, all the methods that take into account propagation effects outside an array should be parametrized to allow for large deviations from the great-circle. In previous 3-D imaging (Bruneton et al. 2004; Salaün et al. 2012) we observed that the single main parameter that improved fit to data was the propagation direction, and that curvatures in the wave front remained a secondary effect.

Finally, while the average absolute deviations are well predicted by the numerical simulations, the deviations for each earthquake are not. For example, variations in crustal thickness of such global models as crust2.0 (Bassin et al. 2000), are not yet sufficiently refined to accurately model wave propagation at short periods (20-40 s), in spite of the large-scale crustal heterogeneities being included, such as mountain belts and differences between crustal structure of oceans and continents. The model should additionally be sufficiently refined in the source area to model the wave-structure interaction in the source area.

At longer periods the deviations remain significant, $3^{\circ}-4^{\circ}$, even though they decrease as the influence of the crust decreases. In comparison, the numerical simulations have mean absolute deviations of approximately $2^{\circ}$. A small damping and smoothing of the amplitude of the velocity anomalies in the mantle may well account for the difference between the simulations and the earthquake data, but some part may also be attributed to the presence of noise. In 
contrast with the short periods, the numerical simulations overall explain many of the deviations observed on earthquake data, in spite of smaller amplitudes. This means that in practice it is possible to use the information from numerical simulations to correct for propagation direction at long periods, if it is not possible to estimate it from local seismic stations. Additionally, it is possible for the global surface wave tomographies currently based on great-circle propagation to use forward modelling for approximated corrections; this would avoid the small bias towards higher velocities that otherwise occurs. Whether ray tracing is sufficient to do the forward calculation remains to be more systematically tested (see also Foster et al. 2014b).

The comparison of event data with noise correlations in the period interval 20-60 s shows very good agreement, despite a lower signalto-noise ratio of the noise correlations. As the noise correlations of vertical-vertical components correspond to vertical displacement created by a vertical point source, the agreement with event data implies that, in agreement with the numerical simulations, the deviations are dominated by the large-scale propagation between source and receivers, and that the observed spatial variations are independent of source mechanisms. This comparison also demonstrates that the noise correlations fully capture the complex surface wave propagation between two points also at teleseismic distances.

\section{ACKNOWLEDGEMENTS}

Continuous records used to compute the correlation data set shown in this study were obtained through the IRIS, NIED and RESIF data centres. We used data from numerous seismic networks, and we thank all of the dedicated seismologists and technical staff who run these networks and make their seismic data available. We in particular thank all the researchers and engineers involved in the acquisition and distribution of data from the LAPNET array. The maps were drawn with the Generic Mapping Tool (Wessel \& Smith 1998). This study was partly supported by the European Research Council through the advanced grant Whisper 227507 and by ITN QUEST. Synthetic seismograms have been computed on the cluster Froggy from the CIMENT consortium of the University of Grenoble, using the SPECFEM Globe software (http://geodynamics.org/cig/software/specfem3d_globe/). Constructive comments to the two versions of the manuscript are greatly appreciated.

\section{REFERENCES}

Alsina, D. \& Snieder, R., 1996. Constraints on the velocity structure beneath the Tornquist-Teisseyre Zone from beamforming analysis, Geophys. J. Int., 126, 205-218.

Alsina, D., Snieder, R. \& Maupin, V., 1993. A test of the great-circle approximation in the analysis of surface waves, Geophys. Res. Lett., 20, 915-918.

Alvizuri, C. \& Tanimoto, T., 2011. Azimuthal anisotropy from array analysis of Rayleigh waves in Southern California, Geophys. J. Int., 186, 11351151.

Ardhuin, F., Gualtieri, L. \& Stutzmann, E., 2015. How ocean waves rock the Earth: two mechanisms explain microseisms with periods 3 to $300 \mathrm{~s}$, Geophys. Res. Lett., 42, 765-772.

Bassin, C., Laske, G. \& Masters, G., 2000. The current limits of resolution for surface wave tomography in North America, EOS, Trans. Am. geophys. Un., 81, F897.

Baumont, D., Paul, A., Zandt, G., Beck, S. \& Pedersen, H.A., 2002. Lithospheric structure beneath the Central Andes based on surface wave dispersion, J. geophys. Res., 107, doi:10.1029/2001/JB00034.
Boué, P., Poli, P., Campillo, M. \& Roux, P., 2014. Reverberations, coda waves and ambient noise: correlations at the global scale and retrieval of the deep phases, Earth planet. Sci. Lett., 391, 137-145.

Bourova, E., Kassaras, I., Pedersen, H.A., Yanovskaya, T., Hatzfeld, H. \& Kiratzi, A., 2005. Surface-wave tomography in the Aegean Region, Geophys. J. Int., 160, 1006-1019.

Bruneton, M., Farra, V. \& Pedersen, H.A., 2002. Non-linear surface wave phase inversion based on ray-theory, Geophys. J. Int., 151, 583-596.

Bruneton, M. et al., 2004. Layered lithospheric mantle in the central Baltic Shield from surface waves and xenolith analysis, Earth planet. Sci. Lett., 226, 41-52.

Bungum, H. \& Capon, J., 1974. Coda pattern and multipath propagation of Rayleigh waves at NORSAR, Phys. Earth planet. Inter., 9, 111-127.

Campillo, M. \& Roux, P., 2014. Seismic imaging and monitoring with ambient noise correlations, in Treatise on Geophysics, Vol. 1, pp. 256271, 2nd edn, eds Romanowicz, B. \& Dziewonski, A., Elsevier.

Chen, P., Jordan, T.H. \& Zhao, L., 2007. Full 3D tomography: a comparison between the scattering-integral and adjoint-wavefield methods, Geophys J. Int., 170(1), 175-181.

Chevrot, S. \& Zhao, L., 2007. Multiscale finite-frequency Rayleigh wave tomography of the Kaapvaal craton, Geophys. J. Int., 169, 201-215.

Cotte, N., Pedersen, H.A., Campillo, M., Farra, V. \& Cansi, Y., 2000. Offgreat-circle propagation of intermediate period surface waves as observed on a dense array in the French Alps, Geophys. J. Int., 142, 825-840.

Cupillard, P., Delavaud, E., Burgos, G., Festa, G., Vilotte, J.P., Capdeville, Y. \& Montagner, J.-P., 2012. RegSEM: a versatile code based on the spectral element method to compute seismic wave propagation at the regional scale, Geophys. J. Int., 188, 1203-1220.

Debayle, E., Kennett, B. \& Priestley, K., 2005. Global azimuthal seismic anisotropy and the unique plate-motion deformation of Australia, Nature, 433, 509-512.

Dziewonski, A.M. \& Anderson, D.L., 1981. Preliminary reference Earth model, Phys. Earth planet. Inter., 25, 297-356.

Dziewonski, A.M., Chou, T.-A. \& Woodhouse, J.H., 1981. Determination of earthquake source parameters from waveform data for studies of global and regional seismicity, J. geophys. Res., 86, 2825-2852.

Ekström, G. \& Busby, R.W., 2008. Measurements of seismometer orientation at US-Array Transportable Array and Backbone stations, Seism. Res. Lett., 79(4), 554-561.

Ekström, G., Nettles, M. \& Dziewonski, A.M., 2012. The global CMT project 2004-2010: centroid-moment tensors for 13017 earthquakes, Phys. Earth planet. Inter., 200-201, 1-9.

Ferreira, A.M.G. \& Woodhouse, J.H., 2007. Source, path and receiver effects on surface waves, Geophys. J. Int., 168, 109-232.

Fichtner, A., Igel, H., Bunge, H.P. \& Kennett, B.L.N., 2009. Simulation and inversion of seismic wave propagation on continental scales based on a spectral-element method, J. Numer. Anal., Indust. Appl. Math., 4, $11-22$.

Fichtner, A., Trampert, J., Cupillard, P., Saygin, E., Taymaz, T., Capdeville, Y. \& Villaseñor, A., 2013. Multiscale full waveform inversion, Geophys. J. Int., 194, 534-556.

Foster, A., Ekström, G. \& Nettles, M., 2014a. Surface wave phase velocities of the Western United States from a two-station method, Geophys. J. Int., 196(2), 1189-1206.

Foster, A., Ekström, G. \& Hjörleifsdottir, V., 2014b. Arrival-angle anomalies across the USArray Transportable Array, Earth planet. Sci. Lett., 402, 5868.

Friederich, W., 2003. The S-velocity structure of the East Asian mantle from inversion of shear and surface waveforms, Geophys. J. Int., 153, 88-102

Friederich, W. \& Wielandt, E., 1995. Interpretation of seismic surface waves in regional networks: joint estimation of wave-field geometry and local phase velocity, method and numerical tests, Geophys. J. Int., 120, 731-744.

Froment, B., Campillo, M., Roux, P., Gouédard, P., Verdel, A. \& Weaver, R.L., 2010. Estimation of the effect of nonisotropically distributed energy on the apparent arrival time in correlations, Geophysics, 75(5), SA85SA93. 
Kaviani, A., Paul, A., Bourova, E., Hatzfeld, D., Pedersen, H. \& Mokhtari, M., 2007. A strong seismic velocity contrast in the shallow mantle across the Zagros collision zone (Iran), Geophys. J. Int., 171, 399-410.

Kimman, W.P. \& Trampert, J., 2010. Approximations in seismic interferometry and their effects on surface waves, Geophys. J. Int., 182(1), 461476.

Komatitsch, D. \& Tromp, J., 2002a. Spectral-element simulations of global seismic wave propagation - I. Validation, Geophys. J. Int., 149, 390412

Komatitsch, D. \& Tromp, J., 2002b. Spectral-element simulations of global seismicwave propagation - II. 3-D models, oceans, rotation, selfgravitation, Geophys. J. Int., 150, 303-318.

Komatitsch, D. \& Vilotte, J.P., 1998. The spectral element method: an efficient tool to simulate the seismic response of 2D and 3D geological structures, Bull. seism. Soc. Am., 88, 368-392.

Larson, E.W.F. \& Ekström, G., 2002. Determining surface wave arrival angle anomalies, J. geophys. Res., 107(B6), 2127, doi:10.1029/2000JB000048.

Laske, G., 1995. Global observation of off-great-circe propagation of long period surface waves, Geophys. J. Int., 123, 245-259.

Laske, G. \& Masters, G., 1996. Constraints on global phase velocity maps from long-period polarization data, J. geophys. Res., 101, 16 059-16 075.

Laske, G. \& Masters, G., 1998. Surface-wave polarization data and global anisotropic structure, Geophys. J. Int., 132(3), 508-520.

Lerner-Lam, A.L. \& Park, J., 1989. Frequency-dependent refraction and multipathing of 10-100 second surface waves in the western Pacific, Geophys. Res. Lett., 16(6), 527-530.

Levshin, A., Yanovskaya, T., Lander, A., Buckin, B., Barmin, M., Ratnikova, L. \& Its, E., 1989. Seismic Surface Waves in a Laterally Inhomogeneous Earth, pp. 35-69, ed. Keilis-Borok, V.I., Kluwer.

Li, A., Forsyth, D.W. \& Fischer, K., 2003. Shear velocity structure and azimuthal anisotropy beneath eastern North America from Rayleigh wave inversion, J. geophys. Res., 108, 2362, doi:10.1029/2002JB002259.

Lin, F.C. \& Ritzwoller, M.H., 2011. Helmholtz surface wave tomography for isotropic and azimuthally anisotropic structure, Geophys. J. Int., 186, doi:10.1111/j.1365-246X.2011.05070.x.

Maupin, V., 1996. The radiation modes of a vertically varying half-space: a new representation of the complete Green's function in terms of modes, Geophys. J. Int., 126(3), 762-780.

Maupin, V., 2011. Upper-mantle structure in southern Norway from beamforming of Rayleigh wave data presenting multipathing, Geophys. J. Int., 185(2), 985-1002.

Padovani, E., Priolo, E. \& Seriani, G., 1994. Low and high order finite element method: experience in seismic modeling, J. Comput. Acoust., 02(04), 371-422.

Paulssen, H., Levshin, A.L., Levander, A.V. \& Snieder, R., 1990. Timeand frequency-dependent polarization analysis: anomalous surface wave obesrvations in Iberia, Geophys. J. Int., 103, 483-496.

Pedersen, H.A., 2006. Impacts of non-plane waves on two-station measurements of phase velocities, Geophys. J. Int., 165, 279-287.

Pedersen, H.A., Debayle, E., Maupin, V. \& the POLENET/LAPNET Working Group, 2013. Strong lateral variations of lithospheric mantle beneath cratons - example from the Baltic Shield, Earth planet. Sci. Lett., 383, 164-172.

Peter, D. et al., 2011. Forward and adjoint simulations of seismic wave propagation on fully unstructured hexahedral meshes, Geophys. J. Int., 186, 721-739.

Poli, P., Pedersen, H.A., Campillo, M. \& the POLENET/LAPNET Working Group, 2013. Noise directivity and group velocity tomography in a region with small velocity contrasts: the northern Baltic shield, Geophys. J. Int., 192, 413-424.

Ritsema, J., van Heijst, H.J., Deuss, A. \& Woodhouse, J.H., 2011. S40RTS: a degree-40 shear-velocity model for the mantle from new Rayleigh wave dispersion, teleseismic traveltimes, and normal-mode splitting function measurements, Geophys. J. Int., 184, doi:10.1111/j.1365246X.2010.04884.x.

Ritzwoller, M.H., Shapiro, N.M., Barmin, M.P. \& Levshin, A.L., 2002. Global surface wave diffraction tomography, J. geophys. Res., 107(B12), 2335, doi:10.1029/2002JB001777.
Rost, S. \& Thomas, C., 2002. Array seismology: methods and applications, Rev. Geophys., 40(3), 2-1-2-27.

Salaün, G. et al., 2012. High resolution surface wave tomography beneath the Aegean-Anatolia region: constraints on upper-mantle structure, Geophys. J. Int., 190, 406-420.

Shapiro, N.M. \& Campillo, M., 2004. Emergence of broadband Rayleigh waves from correlations of the ambient seismic noise, Geophys. Res. Lett., 31, L07614, doi:10.1029/2004GL019491.

Silvennoinen, H., Kozlovskaya, E., Kissling, E., Kosarev, G. \& the POLENET/LAPNET Working Group, 2014. A new Moho boundary map for the northern Fennoscandian Shield based on combined controlledsource seismic and receiver function data, GeoRes. J., 1-2, 19-32.

Snieder, R., 1986.3-D linearized scattering of surface waves and a formalism for surface wave holography, Geophys. J. R. astr. Soc., 84, 581-605.

Tanimoto, T. \& Prindle, K., 2002. Three-dimensional $S$-wave velocity structure in Southern California, Geophys. Res. Lett., 29(8), 64-1-64-4.

Tanimoto, T. \& Prindle, K., 2007. Surface wave analysis with beamforming, Earth Planets Space, 59, 453-458.

Traer, J. \& Gerstoft, P., 2014. A unified theory of microseisms and hum, $J$. geophys. Res.: Solid Earth, 119(4), 3317-3339.

Vidale, J.E., 1986. Complex polarization analysis of particle motion, Bull. seism. Soc. Am., 76, 1393-1405.

Wang, Z. \& Dahlen, F.A., 1995. Validity of surface-wave ray theory on a laterally heterogeneous Earth, Geophys. J. Int., 123, 757-773.

Wapenaar, K., 2004. Retrieving the elastodynamic Green's function of an arbitrary inhomogeneous medium by cross correlation, Phys. Rev. Lett., 93(25), 254301

Wessel, P. \& Smith, W.H.F., 1998. New, improved version of generic mapping tools released, EOS, Trans. Am. geophys. Un., 79(47), 579-579.

Woodhouse, J. H. \& Wong, Y. K., 1986. Amplitude, phase and path anomalies of mantle waves, Geophys. J. R. astr. Soc., 87, 753-773.

Yoshizawa, K. \& Kennett, B.L.N., 2002. Determination of the influence zone for surface wave paths, Geophys. J. Int., 149, 440-453.

Yoshizawa, K., Yomogida, K. \& Tuboi, S., 1999. Resolving power of surface wave polarization data for higher-order heterogeneities, Geophys. J. Int., 138, 205-220.

Zhang, J., Walter, W.R., Lay, T. \& Wu, R.-S., 2003. Time-domain pure-state polarization analysis of surface waves traversing California, Pure appl. Geophys., 160, 1447-1478.

Zhou, Y., Dahlen, F.A. \& Nolet, G., 2004. Three-dimensional sensitivity kernels for surface wave observables, Geophys. J. Int., 158, 142-168.

\section{SUPPORTING INFORMATION}

Additional Supporting Information may be found in the online version of this paper:

Figure S1. Example of seismic section for event 3 (see Fig. 1) after pre-processing and frequency-time filtering.

Figure S2. Deviations at $40 \mathrm{~s}$ period using the synthetic seismograms (second figure in left-hand column of Fig. 8). The deviation is shown within in the coloured part of the focal mechanisms as blue-red colour scale, while the hypocentre depth is shown in a white-red-black colour scale in locations shifted SSW from the epicentre.

Figure S3. The ratio of Apparent to True phase velocity using two-station measurements. $\theta$ is the angle between the great-circle event-furthest station, and $\phi$ is the angle between that great-circle and the real arrival direction. (http://gji.oxfordjournals.org/lookup/ supp1/doi:10.1093/gji/ggv382/-/DC1).

Please note: Oxford University Press is not responsible for the content or functionality of any supporting materials supplied by the authors. Any queries (other than missing material) should be directed to the corresponding author for the paper. 